\title{
Guidelines for the Prevention of Intravascular Catheter-related Infections
}

\author{
Naomi P. 0'Grady, ${ }^{1}$ Mary Alexander, ${ }^{2}$ Lillian A. Burns, ${ }^{3}$ E. Patchen Dellinger, ${ }^{4}$ Jeffrey Garland, ${ }^{5}$ Stephen 0. Heard, ${ }^{6}$ Pamela \\ A. Lipsett, ${ }^{7}$ Henry Masur, ${ }^{1}$ Leonard A. Mermel, ${ }^{8}$ Michele L. Pearson, ${ }^{9}$ Issam I. Raad, ${ }^{10}$ Adrienne G. Randolph, ${ }^{11}$ Mark \\ E. Rupp, ${ }^{12}$ Sanjay Saint, ${ }^{13}$ and the Healthcare Infection Control Practices Advisory Committee (HICPAC) (Appendix 1)
}

${ }^{1}$ Critical Care Medicine Department, National Institutes of Health, Bethesda, Maryland; ${ }^{2}$ Infusion Nurses Society, Norwood, Massachusetts; ${ }^{3}$ Staten Island University Hospital, Staten Island, New York; " Department of Surgery, University of Washington, Seattle, Washington; ${ }^{5}$ Department of Pediatrics, Wheaton Franciscan Healthcare-St. Joseph, Milwaukee, Wisconsin; ${ }^{6}$ Department of Anesthesiology, University of Massachusetts Medical School, Worcester, Massachusetts; ${ }^{7}$ Department of Surgery, Johns Hopkins University School of Medicine, Baltimore, Maryland; ${ }^{8}$ Division of Infectious Diseases, Warren Alpert Medical School of Brown University and Rhode Island Hospital, Providence, Rhode Island; ${ }^{9}$ Office of Infectious Diseases, CDC, Atlanta, Georgia; ${ }^{10}$ Department of Infectious Diseases, MD Anderson Cancer Center, Houston, Texas; ${ }^{11}$ Department of Anesthesiology, The Children's Hospital, Boston, Massachusetts; ${ }^{12}$ Department of Internal Medicine, University of Nebraska Medical Center, Omaha, Nebraska; and ${ }^{13}$ Department of Internal Medicine, Ann Arbor VA Medical Center and University of Michigan, Ann Arbor, Michigan

These guidelines have been developed for healthcare personnel who insert intravascular catheters and for persons responsible for surveillance and control of infections in hospital, outpatient, and home healthcare settings. This report was prepared by a working group comprising members from professional organizations representing the disciplines of critical care medicine, infectious diseases, healthcare infection control, surgery, anesthesiology, interventional radiology, pulmonary medicine, pediatric medicine, and nursing. The working group was led by the Society of Critical Care Medicine (SCCM), in collaboration with the Infectious Diseases Society of America (IDSA), Society for Healthcare Epidemiology of America (SHEA), Surgical Infection Society (SIS), American College of Chest Physicians (ACCP), American Thoracic Society (ATS), American Society of Critical Care Anesthesiologists (ASCCA), Association for Professionals in Infection Control and Epidemiology (APIC), Infusion Nurses Society (INS), Oncology Nursing Society (ONS), American Society for Parenteral and Enteral Nutrition (ASPEN), Society of Interventional Radiology (SIR), American Academy of Pediatrics (AAP), Pediatric Infectious Diseases Society

Received 31 January 2011; accepted 4 February 2011.

Correspondence: Naomi P. O'Grady, MD, Critical Care Medicine Department, National Institutes of Health, Building 10, Room 2C145, 10 Center Drive MSC 1662 Bethesda, MD 20892 (nogrady@mail.cc.nih.gov).

Clinical Infectious Diseases 2011;52(9):e162-e193

Published by Oxford University Press on behalf of the Infectious Diseases Society of America 2011.

1058-4838/2011/529-0001\$37.00

DOI: $10.1093 /$ cid/cir257
(PIDS), and the Healthcare Infection Control Practices Advisory Committee (HICPAC) of the Centers for Disease Control and Prevention (CDC) and is intended to replace the Guideline for Prevention of Intravascular Catheter-Related Infections published in 2002. These guidelines are intended to provide evidence-based recommendations for preventing intravascular catheter-related infections. Major areas of emphasis include 1) educating and training healthcare personnel who insert and maintain catheters; 2) using maximal sterile barrier precautions during central venous catheter insertion; 3) using a $>0.5 \%$ chlorhexidine skin preparation with alcohol for antisepsis; 4) avoiding routine replacement of central venous catheters as a strategy to prevent infection; and 5) using antiseptic/ antibiotic impregnated short-term central venous catheters and chlorhexidine impregnated sponge dressings if the rate of infection is not decreasing despite adherence to other strategies (i.e, education and training, maximal sterile barrier precautions, and $>0.5 \%$ chlorhexidine preparations with alcohol for skin antisepsis). These guidelines also emphasize performance improvement by implementing bundled strategies, and documenting and reporting rates of compliance with all components of the bundle as benchmarks for quality assurance and performance improvement.

As in previous guidelines issued by CDC and HICPAC, each recommendation is categorized on the basis of existing scientific data, theoretical rationale, 
applicability, and economic impact. The system for categorizing recommendations in this guideline is as follows:

- Category IA. Strongly recommended for implementation and strongly supported by well-designed experimental, clinical, or epidemiologic studies.

- Category IB. Strongly recommended for implementation and supported by some experimental, clinical, or epidemiologic studies and a strong theoretical rationale; or an accepted practice (e.g., aseptic technique) supported by limited evidence. - Category IC. Required by state or federal regulations, rules, or standards.

- Category II. Suggested for implementation and supported by suggestive clinical or epidemiologic studies or a theoretical rationale.

- Unresolved issue. Represents an unresolved issue for which evidence is insufficient or no consensus regarding efficacy exists.

\section{INTRODUCTION}

In the United States, 15 million central vascular catheter (CVC) days (i.e, the total number of days of exposure to CVCs among all patients in the selected population during the selected time period) occur in intensive care units (ICUs) each year [1]. Studies have variously addressed catheter-related bloodstream infections (CRBSI). These infections independently increase hospital costs and length of stay [2-5], but have not generally been shown to independently increase mortality. While 80,000 CRBSIs occur in ICUs each year [1], a total of 250,000 cases of BSIs have been estimated to occur annually, if entire hospitals are assessed [6]. By several analyses, the cost of these infections is substantial, both in terms of morbidity and financial resources expended. To improve patient outcome and to reduce healthcare costs, there is considerable interest by healthcare providers, insurers, regulators, and patient advocates in reducing the incidence of these infections. This effort should be multidisciplinary, involving healthcare professionals who order the insertion and removal of CVCs, those personnel who insert and maintain intravascular catheters, infection control personnel, healthcare managers including the chief executive officer (CEO) and those who allocate resources, and patients who are capable of assisting in the care of their catheters.

The goal of an effective prevention program should be the elimination of CRBSI from all patient-care areas. Although this is challenging, programs have demonstrated success, but sustained elimination requires continued effort. The goal of the measures discussed in this document is to reduce the rate to as low as feasible given the specific patient population being served, the universal presence of microorganisms in the human environment, and the limitations of current strategies and technologies.

\section{SUMMARY OF RECOMMENDATIONS}

\section{Education, Training and Staffing}

1. Educate healthcare personnel regarding the indications for intravascular catheter use, proper procedures for the insertion and maintenance of intravascular catheters, and appropriate infection control measures to prevent intravascular catheter-related infections [7-15]. Category IA

2. Periodically assess knowledge of and adherence to guidelines for all personnel involved in the insertion and maintenance of intravascular catheters [7-15]. Category IA

3. Designate only trained personnel who demonstrate competence for the insertion and maintenance of peripheral and central intravascular catheters. [14-28]. Category IA

4. Ensure appropriate nursing staff levels in ICUs. Observational studies suggest that a higher proportion of "pool nurses" or an elevated patient-to-nurse ratio is associated with CRBSI in ICUs where nurses are managing patients with CVCs [29-31]. Category IB

\section{Selection of Catheters and Sites Peripheral Catheters and Midline Catheters}

1. In adults, use an upper-extremity site for catheter insertion. Replace a catheter inserted in a lower extremity site to an upper extremity site as soon as possible. Category II

2. In pediatric patients, the upper or lower extremities or the scalp (in neonates or young infants) can be used as the catheter insertion site $[32,33]$. Category II

3. Select catheters on the basis of the intended purpose and duration of use, known infectious and non-infectious complications (e.g., phlebitis and infiltration), and experience of individual catheter operators [33-35]. Category IB

4. Avoid the use of steel needles for the administration of fluids and medication that might cause tissue necrosis if extravasation occurs $[33,34]$. Category IA

5. Use a midline catheter or peripherally inserted central catheter (PICC), instead of a short peripheral catheter, when the duration of IV therapy will likely exceed six days. Category II

6. Evaluate the catheter insertion site daily by palpation through the dressing to discern tenderness and by inspection if a transparent dressing is in use. Gauze and opaque dressings should not be removed if the patient has no clinical signs of infection. If the patient has local tenderness or other signs of possible CRBSI, an opaque dressing should be removed and the site inspected visually. Category II

7. Remove peripheral venous catheters if the patients develops signs of phlebitis (warmth, tenderness, erythema or palpable venous cord), infection, or a malfunctioning catheter [36]. Category IB 


\section{Central Venous Catheters.}

1. Weigh the risks and benefits of placing a central venous device at a recommended site to reduce infectious complications against the risk for mechanical complications (e.g., pneumothorax, subclavian artery puncture, subclavian vein laceration, subclavian vein stenosis, hemothorax, thrombosis, air embolism, and catheter misplacement) [37-53]. Category IA

2. Avoid using the femoral vein for central venous access in adult patients $[38,50,51,54]$. Category $1 \mathrm{~A}$

3. Use a subclavian site, rather than a jugular or a femoral site, in adult patients to minimize infection risk for nontunneled CVC placement [50-52]. Category IB

4. No recommendation can be made for a preferred site of insertion to minimize infection risk for a tunneled CVC. Unresolved issue

5. Avoid the subclavian site in hemodialysis patients and patients with advanced kidney disease, to avoid subclavian vein stenosis [53,55-58]. Category IA

6. Use a fistula or graft in patients with chronic renal failure instead of a CVC for permanent access for dialysis [59]. Category $1 \mathrm{~A}$

7. Use ultrasound guidance to place central venous catheters (if this technology is available) to reduce the number of cannulation attempts and mechanical complications. Ultrasound guidance should only be used by those fully trained in its technique. [60-64]. Category $1 \mathrm{~B}$

8. Use a CVC with the minimum number of ports or lumens essential for the management of the patient [65-68]. Category IB

9. No recommendation can be made regarding the use of a designated lumen for parenteral nutrition. Unresolved issue

10. Promptly remove any intravascular catheter that is no longer essential [69-72]. Category IA

11. When adherence to aseptic technique cannot be ensured (i.e catheters inserted during a medical emergency), replace the catheter as soon as possible, i.e, within 48 hours [37,73-76]. Category IB

\section{Hand Hygiene and Aseptic Technique}

1. Perform hand hygiene procedures, either by washing hands with conventional soap and water or with alcohol-based hand rubs (ABHR). Hand hygiene should be performed before and after palpating catheter insertion sites as well as before and after inserting, replacing, accessing, repairing, or dressing an intravascular catheter. Palpation of the insertion site should not be performed after the application of antiseptic, unless aseptic technique is maintained [12,77-79]. Category IB

2. Maintain aseptic technique for the insertion and care of intravascular catheters $[37,73,74,76]$. Category IB

3. Wear clean gloves, rather than sterile gloves, for the insertion of peripheral intravascular catheters, if the access site is not touched after the application of skin antiseptics. Category IC

4. Sterile gloves should be worn for the insertion of arterial, central, and midline catheters $[37,73,74,76]$. Category IA

5. Use new sterile gloves before handling the new catheter when guidewire exchanges are performed. Category II

6. Wear either clean or sterile gloves when changing the dressing on intravascular catheters. Category IC

\section{Maximal Sterile Barrier Precautions}

1. Use maximal sterile barrier precautions, including the use of a cap, mask, sterile gown, sterile gloves, and a sterile full body drape, for the insertion of CVCs, PICCs, or guidewire exchange $[14,75,76,80]$. Category IB

2. Use a sterile sleeve to protect pulmonary artery catheters during insertion [81]. Category IB

\section{Skin Preparation}

1. Prepare clean skin with an antiseptic (70\% alcohol, tincture of iodine, an iodophor or chlorhexidine gluconate) before peripheral venous catheter insertion [82]. Category IB

2. Prepare clean skin with a $>0.5 \%$ chlorhexidine preparation with alcohol before central venous catheter and peripheral arterial catheter insertion and during dressing changes. If there is a contraindication to chlorhexidine, tincture of iodine, an iodophor, or $70 \%$ alcohol can be used as alternatives $[82,83]$. Category IA

3. No comparison has been made between using chlorhexidine preparations with alcohol and povidone-iodine in alcohol to prepare clean skin. Unresolved issue.

4. No recommendation can be made for the safety or efficacy of chlorhexidine in infants aged $<2$ months. Unresolved issue

5. Antiseptics should be allowed to dry according to the manufacturer's recommendation prior to placing the catheter $[82,83]$. Category IB

\section{Catheter Site Dressing Regimens}

1. Use either sterile gauze or sterile, transparent, semipermeable dressing to cover the catheter site [84-87]. Category IA

2. If the patient is diaphoretic or if the site is bleeding or oozing, use a gauze dressing until this is resolved [84-87]. Category II

3. Replace catheter site dressing if the dressing becomes damp, loosened, or visibly soiled $[84,85]$. Category IB

4. Do not use topical antibiotic ointment or creams on insertion sites, except for dialysis catheters, because of their potential to promote fungal infections and antimicrobial resistance $[88,89]$. Category $\mathrm{IB}$

5. Do not submerge the catheter or catheter site in water. Showering should be permitted if precautions can be taken 
to reduce the likelihood of introducing organisms into the catheter (e.g., if the catheter and connecting device are protected with an impermeable cover during the shower) [90-92]. Category IB

6. Replace dressings used on short-term CVC sites every 2 days for gauze dressings. Category II

7. Replace dressings used on short-term CVC sites at least every 7 days for transparent dressings, except in those pediatric patients in which the risk for dislodging the catheter may outweigh the benefit of changing the dressing [87, 93]. Category IB

8. Replace transparent dressings used on tunneled or implanted CVC sites no more than once per week (unless the dressing is soiled or loose), until the insertion site has healed. Category II

9. No recommendation can be made regarding the necessity for any dressing on well-healed exit sites of longterm cuffed and tunneled CVCs. Unresolved issue

10. Ensure that catheter site care is compatible with the catheter material $[94,95]$. Category IB

11. Use a sterile sleeve for all pulmonary artery catheters [81]. Category IB

12. Use a chlorhexidine-impregnated sponge dressing for temporary short-term catheters in patients older than 2 months of age if the CLABSI rate is not decreasing despite adherence to basic prevention measures, including education and training, appropriate use of chlorhexidine for skin antisepsis, and MSB [93, 96-98]. Category 1B

13. No recommendation is made for other types of chlorhexidine dressings. Unresolved issue

14. Monitor the catheter sites visually when changing the dressing or by palpation through an intact dressing on a regular basis, depending on the clinical situation of the individual patient. If patients have tenderness at the insertion site, fever without obvious source, or other manifestations suggesting local or bloodstream infection, the dressing should be removed to allow thorough examination of the site [99-101]. Category IB

15. Encourage patients to report any changes in their catheter site or any new discomfort to their provider. Category II

\section{Patient Cleansing}

Use a $2 \%$ chlorhexidine wash for daily skin cleansing to reduce CRBSI [102-104]. Category II

\section{Catheter Securement Devices}

Use a sutureless securement device to reduce the risk of infection for intravascular catheters [105]. Category II

\section{Antimicrobial/Antiseptic Impregnated Catheters and Cuffs}

Use a chlorhexidine/silver sulfadiazine or minocycline/rifampin -impregnated CVC in patients whose catheter is expected to remain in place $>5$ days if, after successful implementation of a comprehensive strategy to reduce rates of CLABSI, the CLABSI rate is not decreasing. The comprehensive strategy should include at least the following three components: educating persons who insert and maintain catheters, use of maximal sterile barrier precautions, and a $>0.5 \%$ chlorhexidine preparation with alcohol for skin antisepsis during CVC insertion [106-113]. Category IA

\section{Systemic Antibiotic Prophylaxis}

Do not administer systemic antimicrobial prophylaxis routinely before insertion or during use of an intravascular catheter to prevent catheter colonization or CRBSI [114]. Category IB

\section{Antibiotic/Antiseptic Ointments}

Use povidone iodine antiseptic ointment or bacitracin/gramicidin/polymyxin B ointment at the hemodialysis catheter exit site after catheter insertion and at the end of each dialysis session only if this ointment does not interact with the material of the hemodialysis catheter per manufacturer's recommendation [59, 115-119]. Category IB

\section{Antibiotic Lock Prophylaxis, Antimicrobial Catheter Flush and Catheter Lock Prophylaxis}

Use prophylactic antimicrobial lock solution in patients with long term catheters who have a history of multiple CRBSI despite optimal maximal adherence to aseptic technique [120138]. Category II

\section{Anticoagulants}

Do not routinely use anticoagulant therapy to reduce the risk of catheter-related infection in general patient populations [139]. Category II

\section{Replacement of Peripheral and Midline Catheters}

1. There is no need to replace peripheral catheters more frequently than every 72-96 hours to reduce risk of infection and phlebitis in adults $[36,140,141]$. Category $1 \mathrm{~B}$

2. No recommendation is made regarding replacement of peripheral catheters in adults only when clinically indicated [142-144]. Unresolved issue

3. Replace peripheral catheters in children only when clinically indicated $[32,33]$. Category $1 \mathrm{~B}$

4. Replace midline catheters only when there is a specific indication. Category II

\section{Replacement of CVCs, Including PICCs and Hemodialysis Catheters}

1. Do not routinely replace CVCs, PICCs, hemodialysis catheters, or pulmonary artery catheters to prevent catheterrelated infections. Category IB 
2. Do not remove CVCs or PICCs on the basis of fever alone. Use clinical judgment regarding the appropriateness of removing the catheter if infection is evidenced elsewhere or if a noninfectious cause of fever is suspected. Category II

3. Do not use guidewire exchanges routinely for nontunneled catheters to prevent infection. Category IB

4. Do not use guidewire exchanges to replace a nontunneled catheter suspected of infection. Category IB

5. Use a guidewire exchange to replace a malfunctioning nontunneled catheter if no evidence of infection is present. Category IB

6. Use new sterile gloves before handling the new catheter when guidewire exchanges are performed. Category II

\section{Umbilical Catheters}

1. Remove and do not replace umbilical artery catheters if any signs of CRBSI, vascular insufficiency in the lower extremities, or thrombosis are present [145]. Category II

2. Remove and do not replace umbilical venous catheters if any signs of CRBSI or thrombosis are present [145]. Category II

3. No recommendation can be made regarding attempts to salvage an umbilical catheter by administering antibiotic treatment through the catheter. Unresolved issue

4. Cleanse the umbilical insertion site with an antiseptic before catheter insertion. Avoid tincture of iodine because of the potential effect on the neonatal thyroid. Other iodinecontaining products (e.g., povidone iodine) can be used [146150]. Category IB

5. Do not use topical antibiotic ointment or creams on umbilical catheter insertion sites because of the potential to promote fungal infections and antimicrobial resistance [88, 89]. Category IA

6. Add low-doses of heparin $(0.25-1.0 \mathrm{U} / \mathrm{ml})$ to the fluid infused through umbilical arterial catheters [151-153]. Category IB

7. Remove umbilical catheters as soon as possible when no longer needed or when any sign of vascular insufficiency to the lower extremities is observed. Optimally, umbilical artery catheters should not be left in place $>5$ days $[145,154]$. Category II

8. Umbilical venous catheters should be removed as soon as possible when no longer needed, but can be used up to 14 days if managed aseptically $[155,156]$. Category II

9. An umbilical catheter may be replaced if it is malfunctioning, and there is no other indication for catheter removal, and the total duration of catheterization has not exceeded 5 days for an umbilical artery catheter or 14 days for an umbilical vein catheter. Category II

\section{Peripheral Arterial Catheters and Pressure Monitoring Devices for Adult and Pediatric Patients}

1. In adults, use of the radial, brachial or dorsalis pedis sites is preferred over the femoral or axillary sites of insertion to reduce the risk of infection $[46,47,157,158]$. Category IB
2. In children, the brachial site should not be used. The radial, dorsalis pedis, and posterior tibial sites are preferred over the femoral or axillary sites of insertion [46]. Category II

3. A minimum of a cap, mask, sterile gloves and a small sterile fenestrated drape should be used during peripheral arterial catheter insertion $[47,158,159]$. Category IB

4. During axillary or femoral artery catheter insertion, maximal sterile barriers precautions should be used. Category II

5. Replace arterial catheters only when there is a clinical indication. Category II

6. Remove the arterial catheter as soon as it is no longer needed. Category II

7. Use disposable, rather than reusable, transducer assemblies when possible [160-164]. Category IB

8. Do not routinely replace arterial catheters to prevent catheter-related infections [165, 166, 167, 168]. Category II

9. Replace disposable or reusable transducers at 96-hour intervals. Replace other components of the system (including the tubing, continuous-flush device, and flush solution) at the time the transducer is replaced $[37,161]$. Category IB

10. Keep all components of the pressure monitoring system (including calibration devices and flush solution) sterile [160, 169-171]. Category IA

11. Minimize the number of manipulations of and entries into the pressure monitoring system. Use a closed flush system (i.e, continuous flush), rather than an open system (i.e, one that requires a syringe and stopcock), to maintain the patency of the pressure monitoring catheters [163, 172]. Category II

12. When the pressure monitoring system is accessed through a diaphragm, rather than a stopcock, scrub the diaphragm with an appropriate antiseptic before accessing the system [163]. Category IA

13. Do not administer dextrose-containing solutions or parenteral nutrition fluids through the pressure monitoring circuit $[163,173,174]$. Category IA

14. Sterilize reusable transducers according to the manufacturers' instructions if the use of disposable transducers is not feasible [163, 173-176]. Category IA

\section{Replacement of Administration Sets}

1. In patients not receiving blood, blood products or fat emulsions, replace administration sets that are continuously used, including secondary sets and add-on devices, no more frequently than at 96-hour intervals, [177] but at least every 7 days [178-181]. Category IA

2. No recommendation can be made regarding the frequency for replacing intermittently used administration sets.Unresolved issue

3. No recommendation can be made regarding the frequency for replacing needles to access implantable ports. Unresolved issue 
4. Replace tubing used to administer blood, blood products, or fat emulsions (those combined with amino acids and glucose in a 3-in-1 admixture or infused separately) within 24 hours of initiating the infusion [182-185]. Category IB

5. Replace tubing used to administer propofol infusions every 6 or 12 hours, when the vial is changed, per the manufacturer's recommendation (FDA website Medwatch) [186]. Category IA

6. No recommendation can be made regarding the length of time a needle used to access implanted ports can remain in place. Unresolved issue

\section{Needleless Intravascular Catheter Systems}

1. Change the needleless components at least as frequently as the administration set. There is no benefit to changing these more frequently than every 72 hours. [39, 187-193]. Category II

2. Change needleless connectors no more frequently than every 72 hours or according to manufacturers' recommendations for the purpose of reducing infection rates [187, 189, 192, 193]. Category II

3. Ensure that all components of the system are compatible to minimize leaks and breaks in the system [194]. Category II

4. Minimize contamination risk by scrubbing the access port with an appropriate antiseptic (chlorhexidine, povidone iodine, an iodophor, or $70 \%$ alcohol) and accessing the port only with sterile devices [189, 192, 194-196]. Category IA

5. Use a needleless system to access IV tubing. Category IC

6. When needleless systems are used, a split septum valve may be preferred over some mechanical valves due to increased risk of infection with the mechanical valves [197-200]. Category II

\section{Performance Improvement}

Use hospital-specific or collaborative-based performance improvement initiatives in which multifaceted strategies are "bundled" together to improve compliance with evidence-based recommended practices [15, 69, 70, 201-205]. Category IB

\section{BACKGROUND INFORMATION}

\section{Terminology and Estimates of Risk}

The terminology used to identify different types of catheters is confusing, because many clinicians and researchers use different aspects of the catheter for informal reference. A catheter can be designated by the type of vessel it occupies (e.g., peripheral venous, central venous, or arterial); its intended life span (e.g., temporary or short-term versus permanent or long-term); its site of insertion (e.g., subclavian, femoral, internal jugular, peripheral, and peripherally inserted central catheter [PICC]); its pathway from skin to vessel (e.g., tunneled versus nontunneled); its physical length (e.g., long versus short); or some special characteristic of the catheter (e.g., presence or absence of a cuff, impregnation with heparin, antibiotics or antiseptics, and the number of lumens). To accurately define a specific type of catheter, all of these aspects should be described (Table 1).

Likewise the terms used to describe intravascular catheterrelated infections can also be confusing because catheter-related bloodstream infection (CRBSI) and central line-associated bloodstream infection (CLABSI) are often used interchangeably even though the meanings differ.

CRBSI is a clinical definition, used when diagnosing and treating patients, that requires specific laboratory testing that more thoroughly identifies the catheter as the source of the BSI. It is not typically used for surveillance purposes. It is often problematic to precisely establish if a BSI is a CRBSI due to the clinical needs of the patient (the catheter is not always pulled), limited availability of microbiologic methods (many labs do not use quantitative blood cultures or differential time to positivity), and procedural compliance by direct care personnel (labeling must be accurate). Simpler definitions are often used for surveillance purposes. For example, CLABSI is a term used by CDC's National Healthcare Safety Network (NHSN) (NHSN CLABSI information: http://www.cdc.gov/nhsn/psc_da.html) [206]. A CLABSI is a primary BSI in a patient that had a central line within the 48-hour period before the development of the BSI and is not bloodstream related to an infection at another site. However, since some BSIs are secondary to other sources other than the central line (e.g., pancreatitis, mucositis) that may not be easily recognized, the CLABSI surveillance definition may overestimate the true incidence of CRBSI.

\section{Epidemiology and Microbiology in Adult and Pediatric Patients}

National estimates of CLABSI rates are available through CDC's NHSN, a surveillance system for healthcare-associated infections, and are available on CDC's website: http://www.cdc.gov/ nhsn/dataStat.html. A recent report highlights data from 1545 hospitals in 48 States and the District of Columbia that monitor infections in one or more ICUs and/or non-ICUs (e.g., patient care areas, wards) [207]. Because BSI rates are influenced by patient-related factors, such as severity of illness and type of illness (e.g., third-degree burns versus post-cardiac surgery), by catheter-related factors, (such as the condition under which the catheter was placed and catheter type), and by institutional factors (e.g., bed-size, academic affiliation), these aggregate, risk-adjusted rates can be used as benchmarks against which hospitals can make intra- and inter-facility comparisons.

The most commonly reported causative pathogens remain coagulase-negative staphylococci, Staphylococcus aureus, enterococci, and Candida spp [208]. Gram negative bacilli accounted for $19 \%$ and $21 \%$ of CLABSIs reported to CDC [209] and the Surveillance and Control of Pathogens of Epidemiological Importance (SCOPE) database, respectively [208].

For all common pathogens causing CLABSIs, antimicrobial resistance is a problem, particularly in ICUs. Although 
Table 1. Catheters Used for Venous and Arterial Access

\begin{tabular}{|c|c|c|c|}
\hline Catheter type & Entry site & Length & Comments \\
\hline $\begin{array}{l}\text { Peripheral venous } \\
\text { catheters }\end{array}$ & $\begin{array}{l}\text { Usually inserted in veins of forearm } \\
\text { or hand }\end{array}$ & $<3$ inches & $\begin{array}{l}\text { Phlebitis with prolonged use; rarely associated } \\
\text { with bloodstream infection }\end{array}$ \\
\hline $\begin{array}{l}\text { Peripheral arterial } \\
\text { catheters }\end{array}$ & $\begin{array}{l}\text { Usually inserted in radial artery; } \\
\text { can be placed in femoral, axillary, } \\
\text { brachial, posterior tibial arteries }\end{array}$ & $<3$ inches & $\begin{array}{l}\text { Low infection risk; rarely associated with } \\
\text { bloodstream infection }\end{array}$ \\
\hline Midline catheters & $\begin{array}{l}\text { Inserted via the antecubital fossa } \\
\text { into the proximal basilic or cephalic } \\
\text { veins; does not enter central veins, } \\
\text { peripheral catheters }\end{array}$ & 3 to 8 inches & $\begin{array}{l}\text { Anaphylactoid reactions have been reported } \\
\text { with catheters made of elastomeric } \\
\text { hydrogel; lower rates of phlebitis than short } \\
\text { peripheral catheters }\end{array}$ \\
\hline $\begin{array}{l}\text { Nontunneled central } \\
\text { venous catheters }\end{array}$ & $\begin{array}{l}\text { Percutaneously inserted into central } \\
\text { veins (subclavian, internal jugular, } \\
\text { or femoral) }\end{array}$ & $\begin{array}{l}\geqslant 8 \mathrm{~cm} \text { depending } \\
\text { on patient size }\end{array}$ & Account for majority of CRBSI \\
\hline $\begin{array}{l}\text { Pulmonary artery } \\
\text { catheters }\end{array}$ & $\begin{array}{l}\text { Inserted through a Teflon }{ }^{\circledR} \text { introducer } \\
\text { in a central vein (subclavian, } \\
\text { internal jugular, or femoral) }\end{array}$ & $\begin{array}{l}\geqslant 30 \mathrm{~cm} \text { depending } \\
\text { on patient size }\end{array}$ & $\begin{array}{l}\text { Usually heparin bonded; similar rates of } \\
\text { bloodstream infection as CVCs; subclavian } \\
\text { site preferred to reduce infection risk }\end{array}$ \\
\hline $\begin{array}{l}\text { Peripherally inserted } \\
\text { central venous } \\
\text { catheters (PICC) }\end{array}$ & $\begin{array}{l}\text { Inserted into basilic, cephalic, or } \\
\text { brachial veins and enter the } \\
\text { superior vena cava }\end{array}$ & $\begin{array}{l}\geqslant 20 \mathrm{~cm} \text { depending } \\
\text { on patient size }\end{array}$ & Lower rate of infection than nontunneled CVCs \\
\hline $\begin{array}{l}\text { Tunneled central } \\
\text { venous catheters }\end{array}$ & $\begin{array}{l}\text { Implanted into subclavian, internal } \\
\text { jugular, or femoral veins }\end{array}$ & $\begin{array}{l}\geqslant 8 \mathrm{~cm} \text { depending } \\
\text { on patient size }\end{array}$ & $\begin{array}{l}\text { Cuff inhibits migration of organisms into } \\
\text { catheter tract; lower rate of infection than } \\
\text { nontunneled CVC }\end{array}$ \\
\hline Totally implantable & $\begin{array}{l}\text { Tunneled beneath skin and have } \\
\text { subcutaneous port accessed } \\
\text { with a needle; implanted in } \\
\text { subclavian or internal jugular vein }\end{array}$ & $\begin{array}{l}\geqslant 8 \mathrm{~cm} \text { depending } \\
\text { on patient size }\end{array}$ & $\begin{array}{l}\text { Lowest risk for CRBSI; improved patient } \\
\text { self-image; no need for local catheter-site } \\
\text { care; surgery required for catheter removal }\end{array}$ \\
\hline Umbilical catheters & $\begin{array}{l}\text { Inserted into either umbilical vein } \\
\text { or umbilical artery }\end{array}$ & $\begin{array}{l}\leqslant 6 \mathrm{~cm} \text { depending } \\
\text { on patient size }\end{array}$ & $\begin{array}{l}\text { Risk for CRBSI similar with catheters placed } \\
\text { in umbilical vein versus artery }\end{array}$ \\
\hline
\end{tabular}

methicillin-resistant Staphylococcus aureus (MRSA) now account for more than $50 \%$ of all Staphylococcus aureus isolates obtained in ICUs, the incidence of MRSA CLABSIs has decreased in recent years, perhaps as a result of prevention efforts [210]. For gram negative rods, antimicrobial resistance to third generation cephalosporins among Klebsiella pneumoniae and $E$. coli has increased significantly as has imipenem and ceftazidine resistance among Pseudomonas aeruginosa [209]. Candida spp. are increasingly noted to be fluconazole resistant.

\section{Pathogenesis}

There are four recognized routes for contamination of catheters: 1) migration of skin organisms at the insertion site into the cutaneous catheter tract and along the surface of the catheter with colonization of the catheter tip; this is the most common route of infection for short-term catheters [37, 211, 212]; 2) direct contamination of the catheter or catheter hub by contact with hands or contaminated fluids or devices [213, 214];3) less commonly, catheters might become hematogenously seeded from another focus of infection [215]; and 4) rarely, infusate contamination might lead to CRBSI [216].

Important pathogenic determinants of CRBSI are 1) the material of which the device is made; 2) the host factors consisting of protein adhesions, such as fibrin and fibronectin, that form a sheath around the catheter [217]; and 3) the intrinsic virulence factors of the infecting organism, including the extracellular polymeric substance (EPS) produced by the adherent organisms [218]. Some catheter materials also have surface irregularities that enhance the microbial adherence of certain species (e.g., S. epidermidis and C. albicans) $[219,220]$. Catheters made of these materials are especially vulnerable to microbial colonization and subsequent infection. Due to the formation of the fibrin sheath, silastic catheters are associated with higher risk of catheter infections than polyurethane catheters [217]. On the other hand, biofilm formation by C. albicans occurs more readily on silicone elastomer catheter surfaces than polyurethane catheters [219]. Modification of the biomaterial surface properties has been shown to influence the ability of $C$. albicans to form biofilm [220]. Additionally, certain catheter materials are more thrombogenic than others, a characteristic that also might predispose to catheter colonization and infection [221, 222]. This association has led to emphasis on preventing catheter-related thrombus as an additional mechanism for reducing CRBSI $[223,224]$.

The adherence properties of a given microorganism in relationship to host factors are also important in the pathogenesis of CRBSI. For example, S. aureus can adhere to host proteins (e.g., fibrinogen, fibronectin) commonly present on catheters by expressing clumping factors (ClfA and ClfB) that bind to the protein adhesins $[217,222,225,226]$. Furthermore, adherence is enhanced through the production by microbial organisms, such as coagulase negative staphylococci 
[227, 228], S. aureus [229], Pseudomonas aeruginosa [230], and Candida species [231] of an extracellular polymeric substance (EPS) consisting mostly of an exopolysaccharide that forms a microbial biofilm layer $[218,232]$. This biofilm matrix is enriched by divalent metallic cations, such as calcium, magnesium and iron, which make it a solid enclave in which microbial organisms can embed themselves [233-235]. Such a biofilm potentiates the pathogenicity of various microbes by allowing them to withstand host defense mechanisms (e.g., acting as a barrier to engulfment and killing by polymorphonuclear leukocytes) or by making them less susceptible to antimicrobial agents (e.g., forming a matrix that binds antimicrobials before their contact with the organism cell wall or providing for a population of metabolically quiescent, antimicrobial tolerant "persister" cells) [228, 236, 237]. Some Candida spp., in the presence of dextrose-containing fluids, produce slime similar to that of their bacterial counterparts, potentially explaining the increased proportion of BSIs caused by fungal pathogens among patients receiving parenteral nutrition fluids [238].

\section{Strategies for Prevention of Catheter-Related Infections in Adult and Pediatric Patients Education, Training and Staffing}

Recommendations

1. Educate healthcare personnel regarding the indications for intravascular catheter use, proper procedures for the insertion and maintenance of intravascular catheters, and appropriate infection control measures to prevent intravascular catheter-related infections [7-15]. Category IA

2. Periodically assess knowledge of and adherence to guidelines for all personnel involved in the insertion and maintenance of intravascular catheters [7-15]. Category IA

3. Designate only trained personnel who demonstrate competence for the insertion and maintenance of peripheral and central intravascular catheters. [14-28]. Category IA

4. Ensure appropriate nursing staff levels in ICUs. Observational studies suggest that a higher proportion of "pool nurses" or an elevated patient-to-nurse ratio is associated with CRBSI in ICUs where nurses are managing patients with CVCs [29-31]. Category IB

\section{Background}

Well-organized programs that enable healthcare providers to become educated and to provide, monitor, and evaluate care are critical to the success of this effort. Reports spanning the past four decades have consistently demonstrated that risk for infection declines following standardization of aseptic care $[7,12$, $14,15,239-241]$ and that insertion and maintenance of intravascular catheters by inexperienced staff might increase the risk for catheter colonization and CRBSI [15, 242]. Specialized "IV teams" have shown unequivocal effectiveness in reducing the incidence of CRBSI, associated complications, and costs [16-26]. Additionally, infection risk increases with nursing staff reductions below a critical level [30].

\section{Selection of Catheters and Sites Peripheral and Midline Catheter Recommendations}

1. In adults, use an upper-extremity site for catheter insertion. Replace a catheter inserted in a lower extremity site to an upper extremity site as soon as possible. Category II

2. In pediatric patients, the upper or lower extremities or the scalp (in neonates or young infants) can be used as the catheter insertion site $[32,33]$. Category II

3. Select catheters on the basis of the intended purpose and duration of use, known infectious and non-infectious complications (e.g., phlebitis and infiltration), and experience of individual catheter operators [33-35]. Category IB

4. Avoid the use of steel needles for the administration of fluids and medication that might cause tissue necrosis if extravasation occurs $[33,34]$. Category IA

5. Use a midline catheter or peripherally inserted central catheter (PICC), instead of a short peripheral catheter, when the duration of IV therapy will likely exceed six days. Category II

6. Evaluate the catheter insertion site daily by palpation through the dressing to discern tenderness and by inspection if a transparent dressing is in use. Gauze and opaque dressings should not be removed if the patient has no clinical signs of infection. If the patient has local tenderness or other signs of possible CRBSI, an opaque dressing should be removed and the site inspected visually. Category II

7. Remove peripheral venous catheters if the patients develops signs of phlebitis (warmth, tenderness, erythema or palpable venous cord), infection, or a malfunctioning catheter [36]. Category IB

\section{Central Venous Catheters Recommendations}

1. Weigh the risks and benefits of placing a central venous device at a recommended site to reduce infectious complications against the risk for mechanical complications (e.g., pneumothorax, subclavian artery puncture, subclavian vein laceration, subclavian vein stenosis, hemothorax, thrombosis, air embolism, and catheter misplacement) [37-53]. Category IA

2. Avoid using the femoral vein for central venous access in adult patients $[38,50,51,54]$. Category $1 \mathrm{~A}$

3. Use a subclavian site, rather than a jugular or a femoral site, in adult patients to minimize infection risk for nontunneled CVC placement [50-52]. Category IB

4. No recommendation can be made for a preferred site of insertion to minimize infection risk for a tunneled CVC. Unresolved issue 
5. Avoid the subclavian site in hemodialysis patients and patients with advanced kidney disease, to avoid subclavian vein stenosis [53, 55-58]. Category IA

6. Use a fistula or graft in patients with chronic renal failure instead of a CVC for permanent access for dialysis [59]. Category $1 \mathrm{~A}$

7. Use ultrasound guidance to place central venous catheters (if this technology is available) to reduce the number of cannulation attempts and mechanical complications. Ultrasound guidance should only be used by those fully trained in its technique. [60-64]. Category $1 \mathrm{~B}$

8. Use a CVC with the minimum number of ports or lumens essential for the management of the patient [65-68]. Category IB

9. No recommendation can be made regarding the use of a designated lumen for parenteral nutrition. Unresolved issue

10. Promptly remove any intravascular catheter that is no longer essential [69-72]. Category IA

11. When adherence to aseptic technique cannot be ensured (i.e catheters inserted during a medical emergency), replace the catheter as soon as possible, i.e, within 48 hours [37, 73-76]. Category IB

Background

The site at which a catheter is placed influences the subsequent risk for catheter-related infection and phlebitis. The influence of site on the risk for catheter infections is related in part to the risk for thrombophlebitis and density of local skin flora.

As in adults, the use of peripheral venous catheters in pediatric patients might be complicated by phlebitis, infusion extravasation, and catheter infection [243]. Catheter location, infusion of parenteral nutritional fluids with continuous IV fat emulsions, and length of ICU stay before catheter insertion, have all increased pediatric patients' risk for phlebitis. However, contrary to the risk in adults, the risk for phlebitis in children has not increased with the duration of catheterization [243, 244].

The density of skin flora at the catheter insertion site is a major risk factor for CRBSI. No single trial has satisfactorily compared infection rates for catheters placed in jugular, subclavian, and femoral veins. In retrospective observational studies, catheters inserted into an internal jugular vein have usually been associated with higher risk for colonization and/or CRBSI than those inserted into a subclavian [37-47]. Similar findings were noted in neonates in a single retrospective study [245].

Femoral catheters have been demonstrated to have high colonization rates compared with subclavian and internal jugular sites when used in adults and, in some studies, higher rates of CLABSIs [40, 45-47, 50, 51, 246]. Femoral catheters should also be avoided, when possible, because they are associated with a higher risk for deep venous thrombosis than are internal jugular or subclavian catheters [48-50, 53, 247]. One study [38] found that the risk of infection associated with catheters placed in the femoral vein is accentuated in obese patients. In contrast to adults, studies in pediatric patients have demonstrated that femoral catheters have a low incidence of mechanical complications and might have an equivalent infection rate to that of non-femoral catheters [248-251]. Thus, in adult patients, a subclavian site is preferred for infection control purposes, although other factors (e.g., the potential for mechanical complications, risk for subclavian vein stenosis, and catheter-operator skill) should be considered when deciding where to place the catheter.

In two meta-analyses, the use of real-time two-dimensional ultrasound for the placement of CVCs substantially decreased mechanical complications and reduced the number of attempts at required cannulation and failed attempts at cannulation compared with the standard landmark placement [60, 61]. Evidence favors the use of two-dimensional ultrasound guidance over Doppler ultrasound guidance [60]. Site selection should be guided by patient comfort, ability to secure the catheter, and maintenance of asepsis as well as patient-specific factors (e.g., preexisting catheters, anatomic deformity, and bleeding diathesis), relative risk of mechanical complications (e.g., bleeding and pneumothorax), the availability of bedside ultrasound, the experience of the person inserting the catheter, and the risk for infection.

Catheters should be inserted as great a distance as possible from open wounds. In one study, catheters inserted close to open burn wounds (i.e, $25 \mathrm{~cm} 2$ overlapped a wound) were 1.79 times more likely to be colonized and 5.12 times more likely to be associated with bacteremia than catheters inserted farther from the wounds [252].

Type of Catheter Material. Polytetrafluoroethylene (Tef$\operatorname{lon}^{\circledR}$ ) or polyurethane catheters have been associated with fewer infectious complications than catheters made of polyvinyl chloride or polyethylene $[36,253,254]$. Steel needles used as an alternative to catheters for peripheral venous access have the same rate of infectious complications as do Teflon ${ }^{\circledR}$ catheters $[33,34]$. However, the use of steel needles frequently is complicated by infiltration of intravenous (IV) fluids into the subcutaneous tissues, a potentially serious complication if the infused fluid is a vesicant [34].

\section{Hand Hygiene and Aseptic Technique}

\section{Recommendations}

1. Perform hand hygiene procedures, either by washing hands with conventional soap and water or with alcohol-based hand rubs (ABHR). Hand hygiene should be performed before and after palpating catheter insertion sites as well as before and after inserting, replacing, accessing, repairing, or dressing an intravascular catheter. Palpation of the insertion site should not be performed after the application of antiseptic, unless aseptic technique is maintained [12, 77-79]. Category IB

2. Maintain aseptic technique for the insertion and care of intravascular catheters $[37,73,74,76]$. Category IB 
3. Wear clean gloves, rather than sterile gloves, for the insertion of peripheral intravascular catheters, if the access site is not touched after the application of skin antiseptics. Category IC

4. Sterile gloves should be worn for the insertion of arterial, central, and midline catheters $[37,73,74,76]$. Category IA

5. Use new sterile gloves before handling the new catheter when guidewire exchanges are performed. Category II

6. Wear either clean or sterile gloves when changing the dressing on intravascular catheters. Category IC

\section{Background}

Hand hygiene before catheter insertion or maintenance, combined with proper aseptic technique during catheter manipulation, provides protection against infection [12]. Proper hand hygiene can be achieved through the use of either an alcohol-based product [255] or with soap and water with adequate rinsing [77]. Appropriate aseptic technique does not necessarily require sterile gloves for insertion of peripheral catheters; a new pair of disposable nonsterile gloves can be used in conjunction with a "no-touch" technique for the insertion of peripheral venous catheters. Sterile gloves must be worn for placement of central catheters since a "no-touch" technique is not possible.

\section{Maximal Sterile Barrier Precautions}

\section{Recommendations}

1. Use maximal sterile barrier precautions, including the use of a cap, mask, sterile gown, sterile gloves, and a sterile full body drape, for the insertion of CVCs, PICCs, or guidewire exchange $[14,75,76,80]$. Category IB

2. Use a sterile sleeve to protect pulmonary artery catheters during insertion [81]. Category IB

\section{Background}

Maximum sterile barrier (MSB) precautions are defined as wearing a sterile gown, sterile gloves, and cap and using a full body drape (similar to the drapes used in the operating room) during the placement of CVC. Maximal sterile barrier precautions during insertion of CVC were compared with sterile gloves and a small drape in a randomized controlled trial. The MSB group had fewer episodes of both catheter colonization $(\mathrm{RR}=.32,95 \% \mathrm{CI}, .10-.96, P=.04)$ and CR-BSI $(\mathrm{RR}=.16$, $95 \% \mathrm{CI}, .02-1.30, P=.06)$. In addition, the group using MSB precautions had infections that occurred much later and contained gram negative, rather than gram positive, organisms [76]. A study of pulmonary artery catheters also secondarily demonstrated that use of MSB precautions lowered risk of infection [37]. Another study evaluated an educational program directed at improving infection control practices, especially MSB precautions. In this study, MSB precautions use increased and CRBSI decreased [14]. A small trial demonstrated a reduced risk of skin colonization at the insertion site when MSB precautions were used [OR 3.40, 95\%CI 1.32 to 3.67 ] [80].

\section{Skin Preparation}

Recommendations

1. Prepare clean skin with an antiseptic (70\% alcohol, tincture of iodine, an iodophor or chlorhexidine gluconate) before peripheral venous catheter insertion [82]. Category IB

2. Prepare clean skin with a $>0.5 \%$ chlorhexidine preparation with alcohol before central venous catheter and peripheral arterial catheter insertion and during dressing changes. If there is a contraindication to chlorhexidine, tincture of iodine, an iodophor, or $70 \%$ alcohol can be used as alternatives [82, 83]. Category IA

3. No comparison has been made between using chlorhexidine preparations with alcohol and povidone-iodine in alcohol to prepare clean skin. Unresolved issue.

4. No recommendation can be made for the safety or efficacy of chlorhexidine in infants aged $<2$ months. Unresolved issue

5. Antiseptics should be allowed to dry according to the manufacturer's recommendation prior to placing the catheter $[82,83]$. Category IB

\section{Background}

Two well-designed studies evaluating the chlorhexidinecontaining cutaneous antiseptic regimen in comparison with either povidone iodine or alcohol for the care of an intravascular catheter insertion site have shown lower rates of catheter colonization or CRBSI associated with the chlorhexidine preparation [82, 83]. (The comparison of chlorhexidine gluconate alcohol to povidone iodine alcohol has not been done.) When $0.5 \%$ tincture of chlorhexidine was compared with $10 \%$ povidone iodine, no differences were seen in central venous catheter (CVC) colonization or in CRBSI [256]. In a three-armed study ( $2 \%$ aqueous chlorhexidine gluconate vs $10 \%$ povidone-iodine vs $70 \%$ alcohol), $2 \%$ aqueous chlorhexidine gluconate tended to decrease CRBSI compared with $10 \%$ povidone iodine or $70 \%$ alcohol [82]. A meta-analysis of 4,143 catheters suggested that chlorhexidine preparation reduced the risk of catheter related infection by $49 \%$ ( $95 \%$ CI .28 to .88 ) relative to povidone iodine [257]. An economic decision analysis based on available evidence suggested that the use of chlorhexidine, rather than povidone iodine, for CVC care would result in a $1.6 \%$ decrease in the incidence of CRBSI, a $0.23 \%$ decrease in the incidence of death, and a savings of $\$ 113$ per catheter used [258]. While chlorhexidine has become a standard antiseptic for skin preparation for the insertion of both central and peripheral venous catheters, $5 \%$ povidone iodine solution in $70 \%$ ethanol was associated with a substantial reduction of CVC-related colonization and infection compared with $10 \%$ aqueous povidone iodine [259]. 


\section{Catheter Site Dressing Regimens}

Recommendations

1. Use either sterile gauze or sterile, transparent, semipermeable dressing to cover the catheter site [84-87]. Category IA

2. If the patient is diaphoretic or if the site is bleeding or oozing, use gauze dressing until this is resolved [84-87]. Category II

3. Replace catheter site dressing if the dressing becomes damp, loosened, or visibly soiled $[84,85]$. Category IB

4. Do not use topical antibiotic ointment or creams on insertion sites, except for dialysis catheters, because of their potential to promote fungal infections and antimicrobial resistance $[88,89]$. Category IB

5. Do not submerge the catheter or catheter site in water. Showering should be permitted if precautions can be taken to reduce the likelihood of introducing organisms into the catheter (e.g., if the catheter and connecting device are protected with an impermeable cover during the shower) [90-92]. Category IB

6. Replace dressings used on short-term CVC sites every 2 days for gauze dressings. Category II

7. Replace dressings used on short-term CVC sites at least every 7 days for transparent dressings, except in those pediatric patients in which the risk for dislodging the catheter may outweigh the benefit of changing the dressing $[87,93]$. Category IB

8. Replace transparent dressings used on tunneled or implanted CVC sites no more than once per week (unless the dressing is soiled or loose), until the insertion site has healed. Category II

9. No recommendation can be made regarding the necessity for any dressing on well-healed exit sites of longterm cuffed and tunneled CVCs. Unresolved issue

10. Ensure that catheter site care is compatible with the catheter material $[94,95]$. Category IB

11. Use a sterile sleeve for all pulmonary artery catheters [80]. Category IB

12. Use a chlorhexidine-impregnated sponge dressing for temporary short-term catheters in patients older than 2 months of age if the CLABSI rate is not decreasing despite adherence to basic prevention measures, including education and training, appropriate use of chlorhexidine for skin antisepsis, and MSB [93, 96-98]. Category 1B

13. No recommendation is made for other types of chlorhexidine dressings. Unresolved issue

14. Monitor the catheter sites visually when changing the dressing or by palpation through an intact dressing on a regular basis, depending on the clinical situation of the individual patient. If patients have tenderness at the insertion site, fever without obvious source, or other manifestations suggesting local or bloodstream infection, the dressing should be removed to allow thorough examination of the site [99-101]. Category IB
15. Encourage patients to report any changes in their catheter site or any new discomfort to their provider. Category II

Background

Transparent, semi-permeable polyurethane dressings permit continuous visual inspection of the catheter site and require less frequent changes than do standard gauze and tape dressings. In the largest controlled trial of dressing regimens on peripheral catheters, the infectious morbidity associated with the use of transparent dressings on approximately 2,000 peripheral catheters was examined [254]. Data from this study suggest that the rate of colonization among catheters dressed with transparent dressings $(5.7 \%)$ is comparable to that of those dressed with gauze $(4.6 \%)$ and that no clinically substantial differences exist in the incidence of either catheter site colonization or phlebitis. Furthermore, these data suggest that transparent dressings can be safely left on peripheral venous catheters for the duration of catheter insertion without increasing the risk for thrombophlebitis [254].

A meta-analysis has assessed studies that compared the risk for CRBSIs using transparent dressings versus using gauze dressing [260]. The risk for CRBSIs did not differ between the groups. The choice of dressing can be a matter of preference. If blood is oozing from the catheter insertion site, gauze dressing is preferred. Another systemic review of randomized controlled trials comparing gauze and tape to transparent dressings found no significant differences between dressing types in CRBSIs, catheter tip colonization, or skin colonization [261].

Chlorhexidine impregnated dressings have been used to reduce the risk of CRBSI. In the largest multicenter randomized controlled trial published to date comparing chlorhexidine impregnated sponge dressings vs standard dressings in ICU patients, rates of CRBSIs were reduced even when background rates of infection were low. In this study, 1636 patients (3778 catheters, 28931 catheter-days) were evaluated. The chlorhexidine-impregnated sponge dressings decreased the rates of major CRBSIs (10/1953 [0.5\%], 0.6 per 1000 catheter-days vs $19 / 1825$ [1.1\%], 1.4 per 1000 catheter-days; hazard ratio [HR], 0.39 [95\% confidence interval $\{\mathrm{CI}\}, .17-.93] ; P=.03)$ and CRBSIs (6/1953 catheters, 0.40 per 1000 catheter-days vs $17 / 1825$ catheters, 1.3 per 1000 catheter-days; HR, 0.24 [95\% CI, .09-.65]) [93]. A randomized controlled study of polyurethane or a chlorhexidine impregnated sponge dressing in 140 children showed no statistical difference in BSIs; however, the chlorhexidine group had lower rates of CVC colonization [98]. In 601 cancer patients receiving chemotherapy, the incidence of CRBSI was reduced in patients receiving the chlorhexidine impregnated sponge dressing compared with standard dressings $(P=.016$, relative risk 0.54; confidence interval 0.31-.94) [262]. A meta-analysis that included eight randomized controlled trials demonstrated that chlorhexidine impregnated sponge 
dressings are associated with a reduction of vascular and epidural catheter exit site colonization but no significant reduction in CRBSI (2.2\% versus 3.8\%, OR 0.58, 95\% CI: .29-1.14, $P=.11)$ [97].

Although data regarding the use of a chlorhexidine impregnated sponge dressing in children are limited, one randomized, controlled study involving 705 neonates reported a substantial decrease in colonized catheters in infants in the chlorhexidine impregnated sponge dressing group compared with the group that had standard dressings ( $15 \%$ versus $24 \%$; RR $=.6 ; 95 \%$ $\mathrm{CI}=0.5-.9$ ), but no difference in the rates of CRBSI or BSI without a source. Chlorhexidine impregnated sponge dressings were associated with localized contact dermatitis in infants of very low birth weight. In 98 neonates with very low birth weight, 15 (15\%) developed localized contact dermatitis; four (1.5\%) of 237 neonates weighing $>1,000$ g developed this reaction $(P<$ $.0001)$. Infants with gestational age $<26$ weeks who had CVCs placed at age $<8$ days were at increased risk for having localized contact dermatitis, whereas no infants in the control group developed this local reaction [96].

\section{Patient Cleansing}

Recommendation

Use a $2 \%$ chlorhexidine wash for daily skin cleansing to reduce CRBSI [102-104]. Category II

Background

Daily cleansing of ICU patients with a $2 \%$ chlorhexidine impregnated washcloth may be a simple, effective strategy to decrease the rate of primary BSIs. In a single center study of 836 ICU patients, patients receiving the chlorhexidine intervention were significantly less likely to acquire a primary BSI ( 4.1 vs 10.4 infections per 1000 patient days; incidence difference, 6.3 [95\% confidence interval, 1.2-11.0) than those bathed with soap and water [102].

\section{Catheter Securement Devices}

Recommendation

Use a sutureless securement device to reduce the risk of infection for intravascular catheters [105]. Category II

Background

Catheter stabilization is recognized as an intervention to decrease the risk for phlebitis, catheter migration and dislodgement, and may be advantageous in preventing CRBSIs. Pathogenesis of CRBSI occurs via migration of skin flora through the percutaneous entry site. Sutureless securement devices avoid disruption around the catheter entry site and may decrease the degree of bacterial colonization. [105]. Using a sutureless securement device also mitigates the risk of sharps injury to the healthcare provider from inadvertent needlestick injury.

Antimicrobial/Antiseptic Impregnated Catheters and Cuffs Recommendation

Use a chlorhexidine/silver sulfadiazine or minocycline/ rifampin -impregnated CVC in patients whose catheter is expected to remain in place $>5$ days if, after successful implementation of a comprehensive strategy to reduce rates of CLABSI, the CLABSI rate is not decreasing. The comprehensive strategy should include at least the following three components: educating persons who insert and maintain catheters, use of maximal sterile barrier precautions, and a $>0.5 \%$ chlorhexidine preparation with alcohol for skin antisepsis during CVC insertion [106-113]. Category IA

Background

Certain catheters and cuffs that are coated or impregnated with antimicrobial or antiseptic agents can decrease the risk for CRBSI and potentially decrease hospital costs associated with treating CRBSIs, despite the additional acquisition cost of an antimicrobial/antiseptic impregnated catheter [110]. Nearly all of the studies involving antimicrobial/antiseptic-impregnated catheters have been conducted using triple-lumen, uncuffed catheters in adult patients whose catheters remained in place $<30$ days. While most of the studies have been conducted in adults, these catheters have been approved by FDA for use in patients weighing $>3 \mathrm{~kg}$. Two non-randomized studies [112, 113 ] in pediatric ICU patients suggest that these catheters might reduce risk of catheter-associated infection. No antiseptic or antimicrobial impregnated catheters currently are available for use in infants weighing $<3 \mathrm{~kg}$.

Chlorhexidine/Silver Sulfadiazine Catheters coated with chlorhexidine/silver sulfadiazine only on the external luminal surface have been studied as a means to reduce CRBSI. Two meta-analyses of first-generation catheters [1, 263] demonstrated that such catheters reduced the risk for CRBSI compared with standard non-coated catheters. The duration of catheter placement in one study ranged from 5.1 to 11.2 days [264]. A second-generation catheter is now available with chlorhexidine coating the internal surface extending into the extension set and hubs while the external luminal surface is coated with chlorhexidine and silver sulfadiazine. The external surface has three times the amount of chlorhexidine and extended release of the surface bound antiseptics than that in the first generation catheters. All three prospective, randomized studies of second-generation catheters demonstrated a significant reduction in catheter colonization, but they were underpowered to show a difference in CRBSI [106-108]. Prolonged anti-infective activity provides improved efficacy in preventing infections [265]. Although rare, anaphylaxis with the use of these chlorhexidine/silver sulfadiazine catheters has been observed [266-270].

Chlorhexidine/silver sulfadiazine catheters are more expensive than standard catheters. However, one analysis has suggested that the use of chlorhexidine/silver sulfadiazine catheters should lead to a cost savings of $\$ 68$ to $\$ 391$ per catheter [271] in settings in which the risk for CRBSI is high, despite adherence to other preventive strategies (e.g., maximal barrier precautions 
and aseptic techniques). Use of these catheters might be cost effective in ICU patients, burn patients, neutropenic patients, and other patient populations in which the rate of infection exceeds 3.3 per 1,000 catheter days [264].

Minocycline/Rifampin In a multicenter randomized trial, CVCs impregnated on both the external and internal surfaces with minocycline/rifampin were associated with lower rates of CRBSI when compared with the first generation chlorhexidine/ silver sulfadiazine impregnated catheters [109]. The beneficial effect began after day 6 of catheterization. Silicone minocycline/ rifampin impregnated CVCs with an average dwell time of over 60 days have been shown to be effective in reducing CRBSI [111]. No minocycline/rifampin-resistant organisms were reported in these studies. Two trials demonstrated that use of these catheters significantly reduced CRBSI compared with uncoated catheters $[110,111]$. No comparative studies have been published using the second-generation chlorhexidine/silver sulfadiazine catheter. Although there have been concerns related to the potential for development of resistance, several prospective clinical studies have shown that the risk is low [272, 273]. Further, no resistance to minocyline or rifampin related to the use of the catheter has been documented in the clinical setting. Two studies using decision model analysis revealed these catheters were associated with superior cost savings compared with first generation chlorhexidine/silver sulfadiazine catheters [274, 275]. Such analysis needs to be done compared with the second-generation catheters. However, as baseline rates of infection decrease and the cost of catheters decrease, the cost-benefit ratio will likely change.

The decision to use chlorhexidine/silver sulfadiazine or minocycline/rifampin impregnated catheters should be based on the need to enhance prevention of CRBSI after bundled standard procedures have been implemented (e.g., educating personnel, using maximal sterile barrier precautions, and using $>0.5 \%$ chlorhexidine preparation with alcohol for skin antisepsis) and then balanced against the concern for emergence of resistant pathogens and the cost of implementing this strategy.

Platinum/Silver A combination platinum/silver impregnated catheter (i.e, a silver iontophoretic catheter) is available for use in the United States. Several prospective, randomized studies have been published comparing these catheters to uncoated catheters [276-279]. One study showed a reduction in the incidence density of catheter colonization and CRBSI [278], but the other studies found no difference in catheter colonization or CRBSI between the impregnated catheter and a nonimpregnated catheter [39, 276, 277]. In light of this, a firm recommendation for or against the use of these catheters cannot be made.

\section{Systemic Antibiotic Prophylaxis}

Recommendation

Do not administer systemic antimicrobial prophylaxis routinely before insertion or during use of an intravascular catheter to prevent catheter colonization or CRBSI [114]. Category IB

\section{Background}

Several studies have examined the role of systemic antibiotic prophylaxis in prevention of catheter-related infection. A recent meta-analysis reviewed these studies in oncology patients [114]. Four studies used a prophylactic glycopeptide prior to catheter insertion. However, heterogeneity in these studies precludes making any conclusion regarding efficacy.

In a study examining the effect of ongoing oral prophylaxis with rifampin and novobiocin on catheter-related infection in cancer patients treated with interleukin-2 [280], a reduction in CRBSI was observed, even though 9 of 26 subjects (35\%) discontinued the prophylactic antibiotics due to side effects or toxicity. In non-oncology patients, no benefit was associated with vancomycin administration prior to catheter insertion in 55 patients undergoing catheterization for parenteral nutrition [281]. Similarly, extending perioperative prophylactic antibiotics in cardiovascular surgery patients did not reduce central venous catheter colonization [282]. A recent Cochrane review of prophylactic antibiotics in neonates with umbilical venous catheters concluded that there is insufficient evidence from randomized trials to support or refute the use of prophylactic antibiotics [283].

Late onset neonatal sepsis is often due to coagulase negative staphylococci and is thought to frequently stem from infected central venous catheters. Five trials involved a total of 371 neonates comparing vancomycin by continuous infusion via parenteral nutrition or intermittent dosing, and placebo. The infants treated with vancomycin experienced less sepsis (RR .11; 95\% CI .05-.24) and less sepsis due to coagulase negative staphylococci (RR .33; 95\% CI .19-.59) [284]. However, mortality and length of stay were not significantly different between the two groups. There were insufficient data to evaluate the risk of selection for vancomycin resistant organisms.

\section{Antibiotic/Antiseptic Ointments}

\section{Recommendation}

Use povidone iodine antiseptic ointment or bacitracin/ gramicidin/polymyxin $\mathrm{B}$ ointment at the hemodialysis catheter exit site after catheter insertion and at the end of each dialysis session only if this ointment does not interact with the material of the hemodialysis catheter per manufacturer's recommendation [59, 115-119]. Category IB

Background

A variety of topical antibiotic or antiseptic ointments have been utilized in attempts to lower the antimicrobial burden at the catheter insertion site and thus prevent infection. A number of older studies, examining primarily peripheral venous catheters, yielded varying conclusions $[82,285,286]$. In addition, the use of antibiotic ointments that have limited antifungal activity 
may serve to increase colonization and/or infection due to Candida species [89].

More recent studies have examined this approach in highrisk patients, particularly those undergoing hemodialysis [116-119]. Three randomized, controlled trials have evaluated the use of $10 \%$ povidone iodine [117-119]. A significant decrease in colonization, exit-site infection, or bloodstream infection was observed. The beneficial effect was most prominent in subjects with nasal colonization by Staphylococcus aureus [117-119].

Nasal carriers of $S$. aureus are more likely to experience a CRBSI than non-colonized persons [287-289]. This has prompted investigators to assess the utility of topical mupirocin, a potent anti-staphylococcal agent. Several studies have demonstrated a reduced risk of CRBSI when mupirocin ointment was applied at the catheter insertion site [117, 290-292]. Others have shown similar benefits when mupirocin was applied nasally [288, 289, 293]. However, enthusiasm for this measure has been dampened by the rapid emergence of mupirocin resistance observed at some centers [88, 294, 295], and the potential degrading effect that mupirocin has on polyurethane catheters $[94,95]$.

In the only study demonstrating a significant effect on mortality, the application of bacitracin/gramicidin/polymyxin B ointment at the catheter insertion site was compared with placebo in 169 hemodialysis patients [296]. Infections were observed in more patients in the placebo group than in the bacitracin/gramicidin/polymyxin B group (34 versus 12\%; relative risk, $0.35 ; 95 \% \mathrm{CI}, .18$ to .68). The number of infections per 1,000 catheter days $(4.10$ versus $1.02 ; P<.0001)$ and the number of bacteremias per 1,000 catheter days (2.48 versus .63; $P=.0004)$ were also greater in the placebo group. Within the 6-month study period, there were 13 deaths in the placebo group as compared with three deaths in the bacitracin/gramicidin/polymyxin B group $(P=.004)$. Thus, there is evidence from one study in hemodialysis patients that bacitracin/gramicidin/polymyxin B ointment can improve outcome, but no similar data exist for use in other patient populations [296]. It should be noted that the gramicidin-containing ointment is not currently available in the United States.

\section{Antibiotic Lock Prophylaxis, Antimicrobial Catheter Flush and Catheter Lock Prophylaxis}

Recommendation

Use prophylactic antimicrobial lock solution in patients with long term catheters who have a history of multiple CRBSI despite optimal maximal adherence to aseptic technique [120138]. Category II

Background

To prevent CRBSI, a wide variety of antibiotic and antiseptic solutions have been used to flush or lock catheter lumens [120138]. Catheter lock is a technique by which an antimicrobial solution is used to fill a catheter lumen and then allowed to dwell for a period of time while the catheter is idle. Antibiotics of various concentrations that have been used either alone (when directed at a specific organism) or in combination (to achieve broad empiric coverage) to prophylactically flush or lock central venous catheters include vancomycin, gentamicin, ciprofloxacin, minocycline, amikacin, cefazolin, cefotaxime, and ceftazidime; while antiseptics have included alcohol, taurolidine, trisodium citrate. (Taurolidine and trisodium citrate are not approved for this use in the United States). These agents are usually combined with a compound acting as an anticoagulant, such as heparin or EDTA. Most of these studies have been conducted in relatively small numbers of high-risk patients, such as hemodialysis patients, neonates, or neutropenic oncology patients. Although most studies indicate a beneficial effect of the antimicrobial flush or lock solution in terms of prevention of catheter-related infection, this must be balanced by the potential for side effects, toxicity, allergic reactions, or emergence of resistance associated with the antimicrobial agent. The wide variety of compounds used, the heterogeneity of the patient populations studied, and limitations in the size or design of studies preclude a general recommendation for use. In addition, there are no FDA approved formulations approved for marketing, and most formulations have been prepared in hospital pharmacies. A brief overview of some of the studies follows.

At least 10 studies regarding catheter flush or lock solutions have been performed in hemodialysis patients [128, 129, 131138]. Three meta-analyses have all demonstrated that catheter lock solutions reduce risk of CRBSI in hemodialysis patients [297-299]. In the largest of these studies, 291 subjects were enrolled in a prospective randomized comparison of $30 \%$ trisodium citrate versus heparin [133]. The rate of CRBSI was significantly lower in the group whose catheters were locked with trisodium citrate (4.1 BSI/1,000 CVC days vs. 1.1 BSI/1,000 CVC days, $P<.001$ ), and no significant difference in thrombosis or occlusion of the catheter was noted. However, if infused rapidly, concentrated citrate can result in serious hypocalcaemia, cardiac dysrhythmia, and death. The second largest study in hemodialysis subjects examined the effect of a catheter lock solution containing cefazolin, gentamicin, and heparin compared with control patients receiving only heparin [135]. In 120 subjects, the rate of CRBSI was significantly lower in those receiving the antibiotic lock solution (0.44 BSI/1,000 CVC days vs. $3.12 \mathrm{BSI} / 1,000 \mathrm{CVC}$ days, $P=.03$ ) [135]. Other trials in hemodialysis patients have studied minocycline, gentamicin, EDTA, heparin, taurolidine, vancomycin, and cefotaxime.

At least five studies have been conducted in pediatric oncology patients $[120,121,124,126,127]$. In the largest trial, 126 subjects were enrolled in a prospective, randomized, double blind study comparing vancomycin/ciprofloxacin/heparin (VCH) 
to vancomycin/heparin $(\mathrm{VH})$ to heparin $(\mathrm{H})$ alone [124]. The time to CVC-related infection was significantly longer in the $\mathrm{VCH}$ or $\mathrm{VH}$ arms of the study compared with heparin, and the rate of infection was significantly lower with either of the antibiotic containing solutions compared with heparin alone $(1.72 / 1,000 \mathrm{CVC}$ days $[\mathrm{H}]$ vs. $0.55 / 1,000 \mathrm{CVC}$ days $[\mathrm{VCH}]$ vs. $0.37 / 1,000 \mathrm{CVC}$ days $[\mathrm{VH}])$.

In a meta-analysis of seven randomized, controlled trials examining the utility of vancomycin-containing lock or flush solutions compared with heparin alone, the risk ratio for vancomycin/heparin solutions was 0.49 (95\% CI .26-.95, $P=.03$ ) [300]. Use of the catheter lock technique appeared to have greater benefit than simply flushing vancomycin through the catheter.

Recently, a prospective, double blind, randomized trial compared the utility of $70 \%$ ethanol lock versus heparinized saline for the prevention of primary CRBSI in oncology patients. Patients receiving the ethanol lock preventive therapy were significantly less likely to experience a primary CRBSI $(0.60$ / 1,000 CVC days vs. 3.11/1,000 CVC days; OR 0.18, 95\% CI $.05 .65, P=.008)[301]$.

\section{Anticoagulants}

Recommendation

Do not routinely use anticoagulant therapy to reduce the risk of catheter-related infection in general patient populations [139]. Category II

Background

Shortly after insertion, intravascular catheters are coated with a conditioning film, consisting of fibrin, plasma proteins, and cellular elements, such as platelets and red blood cells [213, 302]. Microbes interact with the conditioning film, resulting in colonization of the catheter [303]. There is a close association between thrombosis of central venous catheters and infection [221, 304, 305]. Therefore, anticoagulants have been used to prevent catheter thrombosis and presumably reduce the risk of infection.

In a meta-analysis evaluating the benefit of heparin prophylaxis ( 3 units $/ \mathrm{mL}$ in parenteral nutrition, 5,000 units every 6 or 12 hours flush or 2,500 units low molecular weight heparin subcutaneously) in patients with short-term CVCs, the risk for catheter-related central venous thrombosis was reduced with the use of prophylactic heparin [139]. However, no substantial difference in the rate of CRBSI was observed. In a more recent prospective, randomized trial, 204 patients with non-tunneled catheters were assigned to receive a continuous infusion of heparin (100 units/kg/ d) or saline $(50 \mathrm{~mL} / \mathrm{d})$ [306]. The rate of CRBSI was significantly decreased in the group receiving heparin (2.5 BSI/1,000 CVC days vs. $6.4 \mathrm{BSI} / 1,000 \mathrm{CVC}$ days). Because the majority of heparin solutions contain preservatives with antimicrobial activity, whether any decrease in the rate of CRBSI is a result of the reduced thrombus formation, the preservative, or both is unclear.

The majority of pulmonary artery, umbilical, and central venous catheters are available as heparin-bonded devices. The majority of catheters are heparin bonded with benzalkonium, which provides the catheters with antimicrobial activity [307] and provides an anti-thrombotic effect [308]. However, some catheters have heparin bound directly to the catheter without benzalkonium [309]. Studies have shown that heparin-bonded catheters reduce risk of thrombosis and risk of CRBSI [306, 308310], but are less effective at reducing catheter colonization than catheters impregnated with chlorhexidine/silver sulfadiazine [311]. Unfortunately, heparin-induced thrombocytopenia can occur and has prompted many clinicians to avoid heparin [312]. Trisodium citrate has been recommended as a catheter lock solution because it possesses both anticoagulant and antimicrobial properties [133]. In a prospective, randomized, double blind study in hemodialysis patients, use of interdialytic heparin $(5,000 \mathrm{U} / \mathrm{mL})$ was associated with a significantly greater rate of CRBSIs compared with use of $30 \%$ trisodium citrate (4.1 BSI/ 1,000 CVC days vs. 1.1BSI/1,000 CVC days [313].

Warfarin has been evaluated as a means to reduce CVC thrombus formation and, hence, infection [314-318]. In patients with long-term CVCs, low dose warfarin (i.e., $1 \mathrm{mg} /$ day) reduced the incidence of catheter thrombus [142, 143]. However, other studies have not confirmed reduced thrombosis and still others have found untoward interactions in patients receiving 5-FU [319, 320]. Data are limited; although low dose warfarin decreases the risk of thrombus formation in cancer patients, it has not been shown to reduce infectious complications. Over $20 \%$ of patients in some studies develop prolonged prothrombin times and required dosage adjustment [321]. Other anticoagulants, such as factor Xa inhibitors or direct thrombin inhibitors, have not been adequately assessed in terms of reducing the risk of catheter-associated infection.

\section{Replacement of Peripheral and Midline Catheters} Recommendations

1. There is no need to replace peripheral catheters more frequently than every 72-96 hours to reduce risk of infection and phlebitis in adults $[36,140,141]$. Category $1 \mathrm{~B}$

2. No recommendation is made regarding replacement of peripheral catheters in adults only when clinically indicated [142-144]. Unresolved issue

3. Replace peripheral catheters in children only when clinically indicated $[32,33]$. Category $1 \mathrm{~B}$

4. Replace midline catheters only when there is a specific indication. Category II

\section{Background}

Scheduled replacement of intravascular catheters has been proposed as a method to prevent phlebitis and catheter-related infections. Studies of short peripheral venous catheters indicate that the incidence of thrombophlebitis and bacterial colonization of catheters increases when catheters are left in place $>72$ hours [258]. However, rates of phlebitis are not substantially 
different in peripheral catheters left in place 72 hours compared with 96 hours [141]. Because phlebitis and catheter colonization have been associated with an increased risk for catheter-related infection, short peripheral catheter sites commonly are replaced at 72-96 hour intervals to reduce both the risk for infection and patient discomfort associated with phlebitis.

Some studies have suggested that planned removal at 72 hours vs. removing as needed resulted in similar rates of phlebitis and catheter failure [142-144]. However, these studies did not address the issue of CRBSI, and the risk of CRBSIs with this strategy is not well studied.

Midline catheters are associated with lower rates of phlebitis than short peripheral catheters and with lower rates of infection than CVCs [322-324]. In one prospective study of 140 midline catheters, their use was associated with a BSI rate of 0.8 per 1,000 catheter days [324]. No specific risk factors, including duration of catheterization, were associated with infection. Midline catheters were in place a median of 7 days, but for as long as 49 days. Although the findings of this study suggested that midline catheters could be changed only when there is a specific indication, no prospective, randomized studies have assessed the benefit of routine replacement as a strategy to prevent CRBSI associated with midline catheters.

\section{Replacement of CVCs, Including PICCs and Hemodialysis Catheters}

Recommendations

1. Do not routinely replace CVCs, PICCs, hemodialysis catheters, or pulmonary artery catheters to prevent catheterrelated infections. Category IB

2. Do not remove CVCs or PICCs on the basis of fever alone. Use clinical judgment regarding the appropriateness of removing the catheter if infection is evidenced elsewhere or if a noninfectious cause of fever is suspected. Category II

3. Do not use guidewire exchanges routinely for nontunneled catheters to prevent infection. Category IB

4. Do not use guidewire exchanges to replace a nontunneled catheter suspected of infection. Category IB

5. Use a guidewire exchange to replace a malfunctioning non-tunneled catheter if no evidence of infection is present. Category IB

6. Use new sterile gloves before handling the new catheter when guidewire exchanges are performed. Category II

\section{Background}

Catheter replacement at scheduled time intervals as a method to reduce CRBSI has not lowered rates. Two trials have assessed a strategy of changing the catheter every 7 days compared with a strategy of changing catheters as needed [165, 325]. One of these studies involved 112 surgical ICU patients needing CVCs, pulmonary artery catheters, or peripheral arterial catheters [165], whereas the other study involved only subclavian hemodialysis catheters [325]. In both studies, no difference in CRBSI was observed in patients undergoing scheduled catheter replacement every 7 days compared with patients whose catheters were replaced as needed.

Scheduled guidewire exchange of CVCs is another proposed strategy for preventing CRBSI. The results of a meta-analysis of 12 randomized, controlled trials assessing CVC management failed to demonstrate any reduction of CRBSI rates through routine replacement of CVCs by guidewire exchange compared with catheter replacement on an as needed basis [326]. Thus, routine replacement of CVCs is not necessary for catheters that are functioning and have no evidence of causing local or systemic complications.

Catheter replacement over a guidewire has become an accepted technique for replacing a malfunctioning catheter or exchanging a pulmonary artery catheter for a CVC when invasive monitoring no longer is needed. Catheter insertion over a guidewire is associated with less discomfort and a significantly lower rate of mechanical complications than are those percutaneously inserted at a new site [327]. In addition, this technique provides a means of preserving limited venous access in some patients. Replacement of temporary catheters over a guidewire in the presence of bacteremia is not an acceptable replacement strategy because the source of infection is usually colonization of the skin tract from the insertion site to the vein [37, 327]. However, in selected patients with tunneled hemodialysis catheters and bacteremia, catheter exchange over a guidewire, in combination with antibiotic therapy, is an alternative as a salvage strategy in patients with limited venous access [328-331].

Because of the increased difficulty obtaining vascular access in children, attention should be given to the frequency with which catheters are replaced in these patients. In a study in which survival analysis techniques were used to examine the relation between the duration of central venous catheterization and complications in pediatric ICU patients, all of the patients studied $(\mathrm{n}=397)$ remained uninfected for a median of 23.7 days [250]. In addition, no relation was found between duration of catheterization and the daily probability of infection $(r=$ $0.21 ; P>.1$ ), suggesting that routine replacement of CVCs likely does not reduce the incidence of catheter-related infection [250].

Vascular access sites can be even more limited among neonates. Four randomized trials $(n=368)$ summarized in a recent Cochrane Database Systemic Review compared the effects of giving parenteral nutrition through percutaneous central venous catheters vs. peripheral intravenous catheters. Fewer painful procedures (venipunctures) were required in neonates randomized to percutaneously placed CVCs, and there was no evidence for increased risk of BSIs [332].

CVC occlusion due to thrombus formation is one of the most common reasons for CVC removal in neonates. Various 
methods have been tried to prevent catheter occlusion. Recently, a randomized trial $(n=201)$ evaluated whether a continuous heparin infusion ( 0.5 units $/ \mathrm{kg} /$ hour) could effectively prolong the duration of catheterization when compared with a placebo infusion. The rate of catheter occlusion requiring catheter removal was lower in the heparin group ( $6 \%$ vs. $31 \%, P=.001$ : NNT $=4$ ). Rates of CRBSI were similar, although the study was not powered to evaluate CRBSI rate differences. Heparin associated antibody levels were not routinely measured [333].

Hemodialysis Catheters. The use of catheters for hemodialysis is the most common factor contributing to bacteremia in dialysis patients $[334,335]$. The relative risk for bacteremia in patients with dialysis catheters is sevenfold the risk for patients with arteriovenous (AV) fistulas [336]. AV fistulas and grafts are preferred over hemodialysis catheters in patients with chronic renal failure, due to their lower associated risk of infection. If temporary access is needed for dialysis, a tunneled cuffed catheter is preferable to a non-cuffed catheter, even in the ICU setting, if the catheter is expected to stay in place for $>3$ weeks [59].

Pulmonary Artery Catheters. Pulmonary artery catheters are inserted through a Teflon ${ }^{\circledR}$ introducer and typically remain in place an average of 3 days. The majority of pulmonary artery catheters are heparin bonded, which reduces not only catheter thrombosis but also microbial adherence to the catheter [307]. Meta-analysis indicates that the CRBSI rate associated with pulmonary artery catheterization is 3.7 per 1,000 catheter days and somewhat higher than the rate observed for unmedicated and non-tunnelled CVCs (2.7 per 1,000 catheter days) $[6,45]$.

Data from prospective studies indicate that the risk of significant catheter colonization and CRBSI increases the longer the catheter remains in place. In general, the risk of significant catheter colonization increases after 4 days of catheterization $[75,337,338]$, whereas the risk of CRBSI increases beyond 5-7 days of catheterization $[75,84,166]$. Efforts must be made to differentiate between infection related to the introducer and that related to the pulmonary artery catheter. Significant colonization of the introducer occurs earlier than that of the pulmonary artery catheter [337, 339]. However, no studies indicate that catheter replacement at scheduled time intervals is an effective method to reduce risk of CRBSI [165, 327, 339]. In patients who continue to require hemodynamic monitoring, pulmonary artery catheters do not need to be changed more frequently than every 7 days [339]. No specific recommendation can be made regarding routine replacement of catheters that need to be in place for $>7$ days.

Pulmonary artery catheters are usually packaged with a thin plastic sleeve that prevents touch contamination when placed over the catheter. In a study of 166 catheters, patients who were randomly assigned to have their catheters self-contained within this sleeve had a reduced risk for CRBSI compared with those who had a pulmonary artery catheter placed without the sleeve $(P=.002)[81]$.

\section{Umbilical Catheters}

Recommendations

1. Remove and do not replace umbilical artery catheters if any signs of CRBSI, vascular insufficiency in the lower extremities, or thrombosis are present [145]. Category II

2. Remove and do not replace umbilical venous catheters if any signs of CRBSI or thrombosis are present [145]. Category II

3. No recommendation can be made regarding attempts to salvage an umbilical catheter by administering antibiotic treatment through the catheter. Unresolved issue

4. Cleanse the umbilical insertion site with an antiseptic before catheter insertion. Avoid tincture of iodine because of the potential effect on the neonatal thyroid. Other iodinecontaining products (e.g., povidone iodine) can be used [146150]. Category IB

5. Do not use topical antibiotic ointment or creams on umbilical catheter insertion sites because of the potential to promote fungal infections and antimicrobial resistance $[88,89]$. Category IA

6. Add low-doses of heparin $(0.25-1.0 \mathrm{U} / \mathrm{ml})$ to the fluid infused through umbilical arterial catheters [151-153]. Category IB

7. Remove umbilical catheters as soon as possible when no longer needed or when any sign of vascular insufficiency to the lower extremities is observed. Optimally, umbilical artery catheters should not be left in place $>5$ days $[145,154]$. Category II

8. Umbilical venous catheters should be removed as soon as possible when no longer needed, but can be used up to 14 days if managed aseptically $[155,156]$. Category II

9. An umbilical catheter may be replaced if it is malfunctioning, and there is no other indication for catheter removal, and the total duration of catheterization has not exceeded 5 days for an umbilical artery catheter or 14 days for an umbilical vein catheter. Category II

\section{Background}

Although the umbilical stump becomes heavily colonized soon after birth, umbilical vessel catheterization often is used for vascular access in newborn infants. Umbilical vessels can be cannulated easily and permit both collection of blood samples and measurement of hemodynamic status. The incidences of catheter colonization and BSI are similar for umbilical vein catheters and umbilical artery catheters. In several studies, an estimated $40 \%-55 \%$ of umbilical artery catheters were colonized and 5\% resulted in CRBSI; umbilical vein catheters were associated with colonization in 22\%-59\% of cases $[147,148,340]$ and with CRBSI in $3 \%-8 \%$ of cases 
[148]. Although CRBSI rates are similar for umbilical catheters in the high position (i.e, above the diaphragm) compared with the low position (i.e, below the diaphragm and above the aortic bifurcation), catheters placed in the high position result in a lower incidence of vascular complications without an increase in adverse sequelae [148].

Risk factors for infection differ for umbilical artery and umbilical vein catheters. In one study, neonates with very low birth weight who also received antibiotics for $>10$ days were at increased risk for umbilical artery CRBSIs [148]. In comparison, those with higher birth weight and receipt of parenteral nutrition fluids were at increased risk for umbilical vein CRBSI. Duration of catheterization was not an independent risk factor for infection of either type of umbilical catheter.

A recent randomized trial $(n=210)$ evaluated whether longterm umbilical venous catheterization (up to 28 days) would result in the same or fewer CRBSIs when compared with neonates who were randomized to short-term umbilical venous catheterization for 7-10 days followed by percutaneous central venous catheterization. CRBSI rate was higher (20\%) among long term catheterized neonates when compared with short term catheterized neonates (13\%). The difference was not statistically significant $(P=.17)$, although the study was underpowered. The study was not powered to evaluate differences in venous thrombosis rates [341].

\section{Peripheral Arterial Catheters and Pressure Monitoring Devices for Adult and Pediatric Patients}

Recommendations

1. In adults, use of the radial, brachial or dorsalis pedis sites is preferred over the femoral or axillary sites of insertion to reduce the risk of infection $[46,47,157,158]$. Category IB

2. In children, the brachial site should not be used. The radial, dorsalis pedis, and posterior tibial sites are preferred over the femoral or axillary sites of insertion [46]. Category II

3. A minimum of a cap, mask, sterile gloves and a small sterile fenestrated drape should be used during peripheral arterial catheter insertion $[47,158,159]$. Category IB

4. During axillary or femoral artery catheter insertion, maximal sterile barriers precautions should be used. Category II

5. Replace arterial catheters only when there is a clinical indication. Category II

6. Remove the arterial catheter as soon as it is no longer needed. Category II

7. Use disposable, rather than reusable, transducer assemblies when possible [160-164]. Category IB

8. Do not routinely replace arterial catheters to prevent catheter-related infections [165, 166, 167, 168]. Category II

9. Replace disposable or reusable transducers at 96-hour intervals. Replace other components of the system (including the tubing, continuous-flush device, and flush solution) at the time the transducer is replaced [37, 161]. Category IB

10. Keep all components of the pressure monitoring system (including calibration devices and flush solution) sterile [160, 169-171]. Category IA

11. Minimize the number of manipulations of and entries into the pressure monitoring system. Use a closed flush system (i.e, continuous flush), rather than an open system (i.e, one that requires a syringe and stopcock), to maintain the patency of the pressure monitoring catheters [163, 172]. Category II

12. When the pressure monitoring system is accessed through a diaphragm, rather than a stopcock, scrub the diaphragm with an appropriate antiseptic before accessing the system [163]. Category IA

13. Do not administer dextrose-containing solutions or parenteral nutrition fluids through the pressure monitoring circuit $[163,173,174]$. Category IA

14. Sterilize reusable transducers according to the manufacturers' instructions if the use of disposable transducers is not feasible [163, 173-176]. Category IA

\section{Background}

Arterial catheters are usually inserted into the radial or femoral artery and permit continuous blood pressure monitoring and blood gas measurements. The risk of CRBSI for arterial catheters is lower than that associated with non-coated, uncuffed, nontunneled short term CVCs (1.7 versus 2.7 per 1,000 catheter days) [6]. However, risk of CRBSI rates are comparable between arterial catheters and coated, uncuffed, non-tunneled short term CVCs [6]. Unlike CVCs, use of full barrier precautions during arterial cannulaton does not appear to reduce the risk of arterial CRBSI $[158,159]$. Nonetheless, when arterial catheters are inserted using a protocol which includes maximum barrier precautions, a very low risk of CRBSI ( $0.41 / 1,000$ catheter days) can be achieved [47]. Although a meta-analysis failed to discern a difference in rates of CRBSI among three sites of insertion (radial, femoral, and axillary) [342], colonization of catheters inserted in the femoral site occurs more often [158]. In addition, a prospective observational study of over 2,900 arterial catheters that were inserted using maximum barrier precautions demonstrated an almost 8 -fold increase in the incidence of CRBSI when the femoral site was used compared with the radial site [343]. Furthermore, there is a greater risk of CRBSI caused by gram-negative bacteria when the femoral site is used [343]. The rates of catheter colonization and CRBSI appear similar between the radial and dorsalis pedis sites [157]. The risk of developing a CRBSI increases with the duration of catheterization [166, 344]; however, the routine changing of arterial catheters at scheduled times does not result in a diminution of the risk of CRBSI [165]. Catheters that need to be in place for $>5$ days should not be routinely changed if no evidence of infection is observed. 


\section{Replacement of Administration Sets}

Recommendations

1. In patients not receiving blood, blood products or fat emulsions, replace administration sets that are continuously used, including secondary sets and add-on devices, no more frequently than at 96-hour intervals, [177] but at least every 7 days [178-181]. Category IA

2. No recommendation can be made regarding the frequency for replacing intermittently used administration sets. Unresolved issue

3. No recommendation can be made regarding the frequency for replacing needles to access implantable ports. Unresolved issue

4. Replace tubing used to administer blood, blood products, or fat emulsions (those combined with amino acids and glucose in a 3-in-1 admixture or infused separately) within 24 hours of initiating the infusion [182-185]. Category IB

5. Replace tubing used to administer propofol infusions every 6 or 12 hours, when the vial is changed, per the manufacturer's recommendation (FDA website Medwatch) [186]. Category IA

6. No recommendation can be made regarding the length of time a needle used to access implanted ports can remain in place. Unresolved issue

\section{Background}

The optimal interval for routine replacement of IV administration sets has been examined in a number of well-controlled studies and meta-analyses. Data from these studies reveal that replacing administration sets no more frequently than 72-96 hours after initiation of use is safe and cost-effective [141, 177, 179-181]. More recent studies suggest that administration sets may be used safely for up to 7 days if used in conjunction with antiseptic catheters or if fluids that enhance microbial growth (e.g., parenteral nutrition or blood) have not been used [216, 345]. When a fluid that enhances microbial growth is infused (e.g., fat emulsions and blood products), more frequent changes of administration sets are indicated as these products have been identified as independent risk factors for CRBSI [182, 216, 346-350].

Little data exist regarding the length of time a needle used to access implanted ports can remain in place and the risk of CRBSI. While some centers have left them in place for several weeks without CRBSI, [351], this practice has not been adequately studied.

\section{Needleless Intravascular Catheter Systems}

Recommendations

1. Change the needleless components at least as frequently as the administration set. There is no benefit to changing these more frequently than every 72 hours. [39, 187-193]. Category II
2. Change needleless connectors no more frequently than every 72 hours or according to manufacturers' recommendations for the purpose of reducing infection rates [187, 189, 192, 193]. Category II

3. Ensure that all components of the system are compatible to minimize leaks and breaks in the system [194]. Category II

4. Minimize contamination risk by scrubbing the access port with an appropriate antiseptic (chlorhexidine, povidone iodine, an iodophor, or $70 \%$ alcohol) and accessing the port only with sterile devices [189, 192, 194-196]. Category IA

5. Use a needleless system to access IV tubing. Category IC

6. When needleless systems are used, a split septum valve may be preferred over some mechanical valves due to increased risk of infection with the mechanical valves [197-200]. Category II

\section{Background}

Stopcocks used for injection of medications, administration of IV infusions, and collection of blood samples represent a potential portal of entry for microorganisms into vascular access catheters and IV fluids. Whether such contamination is a substantial entry point of microorganisms that cause CRBSI has not been demonstrated. Nonetheless, stopcocks should be capped when not being used. In general, closed catheter access systems are associated with fewer CRBSIs than open systems and should be used preferentially [352].

"Piggyback" systems (secondary intermittent infusions delivered through a port on a primary infusion set) are used as an alternative to stopcocks. However, they also pose a risk for contamination of the intravascular fluid if the device entering the rubber membrane of an injection port is exposed to air or if it comes into direct contact with nonsterile tape used to fix the needle to the port. Modified piggyback systems have the potential to prevent contamination at these sites [353].

Attempts to reduce the incidence of sharps injuries and the resultant risk for transmission of bloodborne infections to healthcare personnel have led to the introduction and mandating of needleless infusion systems. There are several types of needleless connectors on the market.

The first type of needleless system connectors consisted of a split septum connector, which is accessed with a blunt cannula instead of a needle (external cannulae activated split septums). Because of the large amount of space in the connector to accommodate the cannula, when the cannula is removed it may result in the creation of negative pressure which may cause blood to be aspirated into the distal lumen, possibly increasing the risk of catheter occlusion or thrombosis. A luer-activated device, which incorporates a valve preventing the outflow of fluid through the connector, was designed to eliminate this problem. Some luer devices require a cap to be attached to the valve when not in use, which can be difficult to maintain aseptically, and therefore they may be prone to contamination. 
Another type of second-generation needleless system addressed the occlusion issue by incorporating positive or neutral fluid displacement to either flush out aspirated blood or prevent its aspiration into infusion catheters.

Use of needleless connectors or mechanical valves appear to be effective in reducing connector colonization in some [196, $354,355]$, but not all studies [356] when compared with stopcocks and caps. In one study [354], the incidence of CRBSI was reduced when the needleless connector was compared with standard stopcocks. Appropriate disinfectants must be used to prevent transmission of microbes through connectors [357]. Some studies have shown that disinfection of the devices with chlorhexidine/alcohol solutions appears to be most effective in reducing colonization $[195,196]$. In addition, the time spent applying the disinfectant may be important. One study found that swiping the luer-activated device with $70 \%$ alcohol for only 3 to 5 seconds did not adequately disinfect the septal surface [358]. However, a number of outbreak investigations have reported increases in CRBSIs associated with a switch from external cannulae activated split septum needleless devices to mechanical valve devices [197, 198, 200, 359]. The reasons for these associations are not known and it is also not known if this is a device-specific or class association, particularly as physical and mechanical properties of needleless connectors vary from device to device. In addition, one investigation found CRBSIs increased with the switch from a luer-activated negative displacement mechanical valve to a luer-activated positive fluid displacement mechanical valve [199]. However in an observational study, a switch from a luer-activated negative displacement mechanical valve to a different luer-activated positive displacement mechanical valve as part of a bundled intervention resulted in a significant decrease in CRBSIs [201]. Potential explanations for outbreaks associated with these devices include difficulty encountered in adequate disinfection of the surface of the connector due to physical characteristics of the plastic housing diaphragm interface, fluid flow properties (laminar vs. turbulent), internal surface area, potential fluid dead space, inadequate flushing of the device due to poor visualization of the fluid flow pathway in opaque devices, and the presence of internal corrugations that could harbor organisms, particularly if the catheters are used to withdraw blood [199]. Some studies have shown that the increase in CRBSIs with the change to lueractivated devices may be related to improper cleaning and infection control practices such as infrequently changing the devices [192, 194]. Additionally, silver-coated connector valves have been FDA approved; however, there are no published randomized trials with this device and no recommendation can be made regarding its use. Likewise, an antiseptic-barrier cap for needleless connectors has been studied in a laboratory setting and appears to be effective in preventing the entry of microorganisms [360], but has not yet been studied in a clinical trial.

\section{Performance Improvement}

\section{Recommendation}

Use hospital-specific or collaborative-based performance improvement initiatives in which multifaceted strategies are "bundled" together to improve compliance with evidence-based recommended practices [15, 69, 70, 201-205]. Category IB

Background

Clinical decision makers, healthcare payers, and patient safety advocates emphasize the importance of translating research findings into everyday practice. Rigorous evaluations of CRBSI preventive practices using study designs with high internal validity and including study populations that optimize external validity remain necessary. Once practices have been determined to be effective and economically efficient, the next step is to implement these evidence-based practices so they become part of routine clinical care. Unfortunately, implementation of evidence-based CRBSI preventive practices in U.S. hospitals has been suboptimal $[361,362]$. In a national survey conducted in March 2005 of over 700 U.S. hospitals, approximately one quarter of U.S. hospitals indicated that either maximal sterile barrier precautions during central line insertion or chlorhexidine gluconate as site disinfectant, two practices widely recommended in the guidelines published in 2002 [363], were not being used routinely [364]. Approximately 15\% of U.S. hospitals reported routinely changing CVCs to prevent infection despite evidence that this practice should no longer be used $[362,364]$.

Accordingly, investigators have attempted various approaches to better translate research findings and evidence-based recommendations into clinical practice. Numerous quality improvement studies have been published during the past several years that have used various methods, such as education of healthcare personnel, audit and feedback, organizational change, and clinical reminders [8-11, 69, 70, 202, 365-367]. The educational interventions primarily targeted hand hygiene, use of maximal sterile barriers during insertion, appropriate insertion site selection, proper site care using chlorhexidine gluconate, and prompt removal of unnecessary catheters. While a large number of before-and-after studies with a few using concurrent control groups $[15,70]$ have been published, no randomized, controlled trial evaluating a quality improvement strategy to prevent CRBSI has been reported [368]. The vast majority of before-and-after studies reported statistically significant decreases in CRBSI rates after a quality improvement strategy was implemented [368]. Additionally, both controlled trials also found statistically significant reductions of CRBSI in the intervention units compared with control units $[15,70]$.

Investigators have also employed multifaceted approaches in which several strategies are bundled together to improve compliance with evidence-based guidelines $[15,69,70]$. One such 
collaborative cohort study [69] of 108 ICUs in Michigan targeted clinicians' use of five evidence-based practices: hand hygiene, maximum barrier precautions, chlorhexidine site disinfection, avoiding the femoral site, and promptly removing unnecessary central venous catheters. In addition to educating clinicians about CRBSI prevention, interventions used included: 1) a central venous catheter cart that contained all the necessary supplies; 2) a checklist to ensure adherence to proper practices; 3) stoppage of procedures in non-emergent situations, if evidence-based practices were not being followed; 4) prompt removal of unnecessary central catheters identified during daily patient rounds; 5) feedback to the clinical teams regarding the number of CRBSI episodes and overall rates; and 6) buy-in from the chief executive officers of the participating hospitals that chlorhexidine gluconate products/solutions would be stocked prior to study initiation. Using an interrupted time series analysis and multivariable regression, the investigators reported a statistically significant $66 \%$ decrease in CRBSI rates approximately 18 months after the intervention began [69] and sustained reductions over time [369]. Specific process and outcome measures for tracking and feedback (i.e rate of central line infections, proportion of central lines placed with all or individual bundle elements performed AND documented) should be identified in individual institutions based on areas that have been identified for performance improvement.

Finally, emphasis on the care and maintenance of catheters once they are in place should be a focus of performance improvement and quality assurance in all programs. A study to assess practice and staff knowledge of CVC post-insertion care and identify aspects of CVC care with potential for improvement revealed several areas of opportunity to improve post-insertion care [370]. Data were recorded on 151 CVCs in 106 patients giving a total of 721 catheter days. In all, 323 breaches in care were identified giving a failure rate of $44.8 \%$, with significant differences between intensive care unit (ICU) and non-ICU wards. Dressings (not intact) and caps (incorrectly placed) were identified as the major lapses in CVC care with 158 and 156 breaches per 1000 catheter days, respectively. Interventions to improve reliability of care should focus on making the implementation of best practice easier to achieve.

\section{Acknowledgments}

Notice to Readers. In 2009, the Centers for Disease Control and Prevention (CDC) and Healthcare Infection Control Practices Advisory Committee (HICPAC) integrated current advances in guideline production and implementation into its development process (http://www.cdc.gov/ hicpac/guidelineMethod/guidelineMethod. html). The new methodology enables CDC and HICPAC to improve the validity and usability of its guidelines while also addressing emerging challenges in guideline development in the area of infection prevention and control. However, the Guidelines for the Prevention of Intravascular Catheter-Related Infections were initiated before the methodology was revised. Therefore, this guideline reflects the development methods that were used for guidelines produced prior to 2009. Future revisions will be performed using the updated methodology.

Financial support. E.P.D. Grant support through the NIH.

Potential conflicts of interest. N.P.O.'G. served as a board member for the ABIM Subspecialty Board for Critical Care Medicine. M.A. is an employee of the Infusion Nurses Society, Honoraria from 3M, Becton Dickinson, Smiths Medical. L.A.B. is a consultant for Institute of Healthcare Improvement, Board membership for Theradoc, Medline. Honoraria from APIC, Clorox. E.P.D. consulting from Merck, Baxter, Ortho-McNeil, Targanta, Schering-Plough, Optimer, Cadence, Cardinal, BDGeneOhm, WebEx, Cerebrio, and Tyco. Grant support through the NIH. Payment for lecture from Merck. Payment for development of educational presentation from Medscape. Travel and meeting expenses paid for by ASHP, IDSA, ASM, American College of Surgeons, NQF, SHEA/CDC, HHS, Trauma Shock Inflammation and Sepsis Meeting (Munich), University of Minnesota. J.G. Honoria from Ethicon. S.O.H. provides research support from Angiotech; Honoraria from Angiotech, Merck. L.A.M provides research support from Astellas, Theravance, Pfizer; Consulting for Ash Access, Cadence, CorMedix, Catheter Connections, Carefusion, Sage, Bard, Teleflex; Payment for manuscript preparation from Catheter Connections. I.I.R. provides research support from Cubist, Enzon, and Basilea;Consulting for Clorox; Stock Equity or Options in Great Lakes Pharmaceuticalsand Inventive Protocol; Speakers Bureau for Cook, Inc.; Royalty income (patents owned by MD Anderson on which Dr. Raad in an inventor: American Medical Systems, Cook, Inc., Cook urological, Teleflex, TyRx, Medtronic, Biomet, Great Lakes Pharmaceuticals. A.R. consulting income from Eisai Pharmaceuticals, Discovery Laboratories. M.E.R. provides research support from Molnlycke, Cardinal Healthcare Foundation, Sanofi-Pasteur, 3M, and Cubist; Consulting from Semprus; Honorarium for lectures from $3 \mathrm{M}$, Carefusion, Baxter and Becton Dickinson. Previously served on Board of Directors for Society for Healthcare Epidemiology of America. All other authors: no conflicts.

\section{Healthcare Infection Control Practices Advisory Committee (HICPAC)}

\section{Chairman}

BRENNAN, Patrick J., MD

Chief Medical Officer

Division of Infectious Diseases

University of Pennsylvania Health System

\section{Membership}

BRATZLER, Dale, DO, MPH

President and CEO

Oklahoma Foundation for Medical Quality

BURNS, Lillian A., MT, MPH

Infection Control Coordinator

Greenwich Hospital, Infectious Diseases Department

ELWARD, Alexis, MD

Assistant Professor, Pediatrics Infectious Diseases

Washington University School of Medicine

Department of Pediatrics

Division of Infectious Diseases

HUANG, Susan, MD, MPH

Assistant Professor, Medical Director, Epidemiology and Infection Prevention 
Division of Infectious Diseases,

UC Irvine School of Medicine

LUNDSTROM, Tammy, MD, JD

Chief Medical Officer

Providence Hospital

MCCARTER, Yvette S., PhD Director,

Clinical Microbiology Laboratory

Department of Pathology

University of Florida Health Science Center

MURPHY, Denise M. RN, MPH, CIC

Vice President, Quality and Patient Safety

Main Line Health System

\section{Executive Secretary}

BELL, Michael R., MD

Deputy Director

Division of Healthcare Quality Promotion

Centers for Disease Control and Prevention

OSTROFF, Stephen, MD

Director, Bureau of Epidemiology

Pennsylvania Department of Health

OLMSTED, Russell N., MPH, CIC

Epidemiologist

Infection Control Services

St. Joseph Mercy Health System

PEGUES, David Alexander, MD

Professor of Medicine, Hospital Epidemiologist

David Geffen School of Medicine at UCLA

PRONOVOST, Peter J., MD, PhD, FCCM

Director, Johns Hopkins Quality and Safety Research Group

Johns Hopkins Quality and Safety Research Group

SOULE, Barbara M., RN, MPA, CIC

Practice Leader

Infection Prevention and Control Services

Joint Commission Resources/Joint Commission

International

SCHECTER, William, P., MD

Professor of Surgery

Department of Surgery

San Francisco General Hospital

\section{Ex-officio Members}

Agency for Healthcare Research and Quality (AHRQ)

BAINE, William B., MD

Senior Medical Advisor

Center for Outcomes and Evidence

Center for Medicare \& Medicaid Services (CMS)

MILLER, Jeannie, RN, MPH

Deputy Director, Office of Clinical Standards and Quality
Food and Drug Administration (FDA)

MURPHEY, Sheila A., MD Branch Chief,

Infection Control Devices

Division of Anesthesiology,

General Hospital Infection Control Dental Devices

Center for Devices and Radiology Health

Liaisons

Advisory Council for the Elimination of Tuberculosis

(ACET)

STRICOF, Rachel L., MPH

New York State Department of Health

American College of Occupational and

Environmental Medicine

RUSSI, Mark, MD, MPH

Professor of Medicine

Yale University School of Medicine

Director, Occupational Health

Yale-New Haven Hospital

American Health Care Assn (AHCA)

FITZLER, Sandra L., RN

Senior Director of Clinical Services

American Hospital Association (AHA)

SCHULMAN, Roslyne, MHA, MBA

Director, Policy Development

Association of Professionals of Infection

Control and Epidemiology, Inc. (APIC)

DeBAUN, Barbara, MSN, RN, CIC

Association of periOperative Registered

Nursed (AORN)

BLANCHARD, Joan C., RN, BSN

Council of State and Territorial Epidemiologists (CSTE)

KAINER, Marion MD, MPH

Director, Hospital Infections and

Antimicrobial Resistance Program

Tennessee Department Health

National Institute of Health (NIH)

HENDERSON, David, MD

Deputy Director for Clinical Care

Associate Director for Hospital Epidemiology and Quality

Improvement NIH Clinical Center

Department of Veterans Affairs (VA)

ROSELLE, Gary A., MD

National Program Director,

Infectious Diseases

VA Central Office

Cincinnati VA Medical Center 


\section{Consumers Union \\ MCGIFFERT, Lisa}

Senior Policy Analyst on Health Issues

Project Director Stop Hospital Infections Organization

Infectious Disease Society of America (IDSA)

Huskins, W. Charles MD, MSc

Division of Pediatric Infectious Diseases

Assistant Professor of Pediatrics Mayo Clinic

Public Health Agency of Canada

PATON, Shirley, RN, MN

Senior Advisor Healthcare Acquired Infections

Center for Communicable Diseases and Infection Control

\section{Society for Healthcare Epidemiology of America (SHEA)}

MARAGAKIS, Lisa, MD

Assistant Professor of Medicine John Hopkins Medical

Institutions

Society of Hospital Medicine

Saint, Sanjay, MD, MPH Director,

Ann Arbor VA Medical Center/University of Michigan Patient

Safety Enhancement Program

\section{The Joint Commission}

WISE, Robert A., MD

Vice President

Division of Standards \& Survey Methods

\section{References}

1. Mermel LA. Prevention of intravascular catheter-related infections. (Erratum: Ann Intern Med 133:395, 2000). Ann Intern Med 2000; 132:391-402.

2. Dimick JB, Pelz RK, Consunji R, Swoboda SM, Hendrix CW, Lipsett PA. Increased resource use associated with catheter-related bloodstream infection in the surgical intensive care unit. Arch Surg 2001; 136:229-34.

3. Warren DK, Quadir WW, Hollenbeak CS, Elward AM, Cox MJ, Fraser VJ. Attributable cost of catheter-associated bloodstream infections among intensive care patients in a nonteaching hospital. Crit Care Med 2006; 34:2084-9.

4. Blot SI, Depuydt P, Annemans L, et al. Clinical and economic outcomes in critically ill patients with nosocomial catheter-related bloodstream infections. Clin Infect Dis 2005; 41:1591-8.

5. Renaud B, Brun-Buisson C. Outcomes of primary and catheterrelated bacteremia. A cohort and case-control study in critically ill patients. Am J Respir Crit Care Med 2001; 163:1584-90.

6. Maki DG, Kluger DM, Crnich CJ. The risk of bloodstream infection in adults with different intravascular devices: a systematic review of 200 published prospective studies. Mayo Clin Proc 2006; 81:1159-71.

7. Yoo S, Ha M, Choi D, Pai H. Effectiveness of surveillance of central catheter-related bloodstream infection in an ICU in Korea. Infect Control Hosp Epidemiol 2001; 22:433-6.

8. Warren DK, Zack JE, Cox MJ, Cohen MM, Fraser VJ. An educational intervention to prevent catheter-associated bloodstream infections in a non-teeaching community medical center. Crit Care Med 2003; 31:1959-63.

9. Warren DK, Zack JE, Mayfield JL, et al. The effect of an education program on the incidence of central venous catheter- associated bloodstream infection in a medical ICU. Chest 2004; 126:1612-8.

10. Warren DK, Cosgrove SE, Diekema DJ, et al. A multicenter intervention to prevent catheter-associated bloodstream infections. Infect Control Hosp Epidemiol 2006; 27:662-9.

11. Higuera F, Rosenthal VD, Duarte P, Ruiz J, Franco G, Safdar N. The effect of process control on the incidence of central venous catheterassociated bloodstream infections and mortality in intensive care units in Mexico. Crit Care Med 2005; 33:2022-7.

12. Coopersmith CM, Rebmann TL, Zack JE, et al. Effect of an education program on decreasing catheter-related bloodstream infections in the surgical intensive care unit. Crit Care Med 2002; 30:59-64.

13. Coopersmith CM, Zack JE, Ward MR, et al. The impact of bedside behavior on catheter-related bacteremia in the intensive care unit. Arch Surg 2004; 139:131-6.

14. Sherertz RJ, Ely EW, Westbrook DM, et al. Education of physiciansin-training can decrease the risk for vascular catheter infection. Ann Intern Med 2000; 132:641-8.

15. Eggimann P, Harbarth S, Constantin MN, Touveneau S, Chevrolet JC, Pittet D. Impact of a prevention strategy targeted at vascular-access care on incidence of infections acquired in intensive care. Lancet 2000; 355:1864-8.

16. Nehme AE. Nutritional support of the hospitalized patient. The team concept. JAMA 1980; 243:1906-8.

17. Soifer NE, Borzak S, Edlin BR, Weinstein RA. Prevention of peripheral venous catheter complications with an intravenous therapy team: a randomized controlled trial. Arch Intern Med 1998; 158:473-7.

18. Tomford JW, Hershey CO, McLaren CE, Porter DK, Cohen DI. Intravenous therapy team and peripheral venous catheter-associated complications. A prospective controlled study. Arch Intern Med 1984; 144:1191-4

19. Scalley RD, Van CS, Cochran RS. The impact of an i.v. team on the occurrence of intravenous-related phlebitis. A 30-month study. J Intraven Nurs 1992; 15:100-9.

20. Palefski SS, Stoddard GJ. The infusion nurse and patient complication rates of peripheral-short catheters. A prospective evaluation. J Intraven Nurs 2001; 24:113-23.

21. Miller JM, Goetz AM, Squier C, Muder RR. Reduction in nosocomial intravenous device-related bacteremias after institution of an intravenous therapy team. J Intraven Nurs 1996; 19:103-6.

22. Hunter MR. Development of a Vascular Access Team in an acute care setting. J Infus Nurs 2003; 26:86-91.

23. Hawes ML. A proactive approach to combating venous depletion in the hospital setting. J Infus Nurs 2007; 30:33-44.

24. Brunelle D. Impact of a dedicated infusion therapy team on the reduction of catheter-related nosocomial infections. J Infus Nurs 2003; 26:362-6.

25. Bosma TL, Jewesson PJ. An infusion program resource nurse consult service: our experience in a major Canadian teaching hospital. J Infus Nurs 2002; 25:310-5.

26. Pierce CA, Baker JJ. A nursing process model: quantifying infusion therapy resource consumption. J Infus Nurs 2004; 27:232-44.

27. Tomford JW, Hershey CO. The i.v. therapy team: impact on patient care and costs of hospitalization. NITA 1985; 8:387-9.

28. Davis D, O’Brien MA, Freemantle N, Wolf FM, Mazmanian P, Taylor-Vaisey A. Impact of formal continuing medical education: do conferences, workshops, rounds, and other traditional continuing education activities change physician behavior or health care outcomes? JAMA 1999; 282:867-74.

29. Alonso-Echanove J, Edwards JR, Richards MJ, et al. Effect of nurse staffing and antimicrobial-impregnated central venous catheters on the risk for bloodstream infections in intensive care units. Infect Control Hosp Epidemiol 2003; 24:916-25.

30. Fridkin SK, Pear SM, Williamson TH, Galgiani JN, Jarvis WR. The role of understaffing in central venous catheter-associated bloodstream infections. Infect Control Hosp Epidemiol 1996; 17:150-8. 
31. Robert J, Fridkin SK, Blumberg HM, et al. The influence of the composition of the nursing staff on primary bloodstream infection rates in a surgical intensive care unit. Infect Control Hosp Epidemiol 2000; 21:12-7.

32. Maki DG, Goldman DA, Rhame FS. Infection control in intravenous therapy. Ann Intern Med 1973; 79:867-87.

33. Band JD, Maki DG. Steel needles used for intravenous therapy. Morbidity in patients with hematologic malignancy. Arch Intern Med 1980; 140:31-4.

34. Tully JL, Friedland GH, Baldini LM, Goldmann DA. Complications of intravenous therapy with steel needles and Teflon catheters. A comparative study. Am J Med 1981; 70:702-6.

35. Ryder MA. Peripheral access options. Surg Oncol Clin N Am 1995; 4:395-427.

36. Maki DG, Ringer M. Risk factors for infusion-related phlebitis with small peripheral venous catheters. A randomized controlled trial. Ann Intern Med 1991; 114:845-54.

37. Mermel LA, McCormick RD, Springman SR, Maki DG. The pathogenesis and epidemiology of catheter-related infection with pulmonary artery Swan-Ganz catheters: a prospective study utilizing molecular subtyping. Am J Med 1991; 91:197S-205.

38. Parienti JJ, Thirion M, Megarbane B, et al. Femoral vs jugular venous catheterization and risk of nosocomial events in adults requiring acute renal replacement therapy: a randomized controlled trial. JAMA 2008; 299:2413-22.

39. Moretti EW, Ofstead CL, Kristy RM, Wetzler HP. Impact of central venous catheter type and methods on catheter-related colonization and bacteraemia. J Hosp Infect 2005; 61:139-45.

40. Nagashima G, Kikuchi T, Tsuyuzaki H, et al. To reduce catheterrelated bloodstream infections: is the subclavian route better than the jugular route for central venous catheterization? J Infect Chemother 2006; 12:363-5.

41. Ruesch S, Walder B, Tramer MR. Complications of central venous catheters: internal jugular versus subclavian access-a systematic review. Crit Care Med 2002; 30:454-60.

42. Sadoyama G, Gontijo Filho PP. Comparison between the jugular and subclavian vein as insertion site for central venous catheters: microbiological aspects and risk factors for colonization and infection. Braz J Infect Dis 2003; 7:142-8.

43. Heard SO, Wagle M, Vijayakumar E, et al. Influence of triple-lumen central venous catheters coated with chlorhexidine and silver sulfadiazine on the incidence of catheter-related bacteremia. Arch Intern Med 1998; 158:81-7.

44. Richet H, Hubert B, Nitemberg G, et al. Prospective multicenter study of vascular-catheter-related complications and risk factors for positive central-catheter cultures in intensive care unit patients. J Clin Microbiol 1990; 28:2520-5.

45. Safdar N, Kluger DM, Maki DG. A review of risk factors for catheterrelated bloodstream infection caused by percutaneously inserted, noncuffed central venous catheters: implications for preventive strategies. Medicine (Baltimore) 2002; 81:466-79.

46. Lorente L, Jimenez A, Iribarren JL, Jimenez JJ, Martin MM, Mora ML. The micro-organism responsible for central venous catheter related bloodstream infection depends on catheter site. Intensive Care Med 2006; 32:1449-50.

47. Traore O, Liotier J, Souweine B. Prospective study of arterial and central venous catheter colonization and of arterial- and central venous catheterrelated bacteremia in intensive care units. Crit Care Med 2005; 33:1276-80.

48. Joynt GM, Kew J, Gomersall CD, Leung VY, Liu EK. Deep venous thrombosis caused by femoral venous catheters in critically ill adult patients. Chest 2000; 117:178-83.

49. Mian NZ, Bayly R, Schreck DM, Besserman EB, Richmand D. Incidence of deep venous thrombosis associated with femoral venous catheterization. Acad Emerg Med 1997; 4:1118-21.

50. Merrer J, De Jonghe B, Golliot F, et al. Complications of femoral and subclavian venous catheterization in critically ill patients: a randomized controlled trial. JAMA 2001; 286:700-7.
51. Goetz AM, Wagener MM, Miller JM, Muder RR. Risk of infection due to central venous catheters: effect of site of placement and catheter type. Infect Control Hosp Epidemiol 1998; 19:842-5.

52. Robinson JF, Robinson WA, Cohn A, Garg K, Armstrong JD, 2nd. Perforation of the great vessels during central venous line placement. Arch Intern Med 1995; 155:1225-8.

53. Trottier SJ, Veremakis C, O’Brien J, Auer AI. Femoral deep vein thrombosis associated with central venous catheterization: results from a prospective, randomized trial. Crit Care Med 1995; 23:52-9.

54. Lorente L, Henry C, Martin MM, Jimenez A, Mora ML. Central venous catheter-related infection in a prospective and observational study of 2,595 catheters. Crit Care 2005; 9:R631-5.

55. Schillinger F, Schillinger D, Montagnac R, Milcent T. Post catheterisation vein stenosis in haemodialysis: comparative angiographic study of 50 subclavian and 50 internal jugular accesses. Nephrol Dial Transplant 1991; 6:722-4.

56. Cimochowski GE, Worley E, Rutherford WE, Sartain J, Blondin J, Harter H. Superiority of the internal jugular over the subclavian access for temporary dialysis. Nephron 1990; 54:154-61.

57. Barrett N, Spencer S, McIvor J, Brown EA. Subclavian stenosis: a major complication of subclavian dialysis catheters. Nephrol Dial Transplant 1988; 3:423-5.

58. Trerotola SO, Kuhn-Fulton J, Johnson MS, Shah H, Ambrosius WT, Kneebone PH. Tunneled infusion catheters: increased incidence of symptomatic venous thrombosis after subclavian versus internal jugular venous access. Radiology 2000; 217:89-93.

59. National Kidney Foundation. III. NKF-K/DOQI Clinical Practice Guidelines for Vascular Access: update 2000. Am J Kidney Dis 2001; 37:S137-81.

60. Hind D, Calvert N, McWilliams R, et al. Ultrasonic locating devices for central venous cannulation: meta-analysis. BMJ 2003; 327:361.

61. Randolph AG, Cook DJ, Gonzales CA, Pribble CG. Ultrasound guidance for placement of central venous catheters: a meta-analysis of the literature. Crit Care Med 1996; 24:2053-8.

62. Froehlich CD, Rigby MR, Rosenberg ES, et al. Ultrasound-guided central venous catheter placement decreases complications and decreases placement attempts compared with the landmark technique in patients in a pediatric intensive care unit. Crit Care Med 2009; 37:1090-6.

63. Lamperti M, Caldiroli D, Cortellazzi P, et al. Safety and efficacy of ultrasound assistance during internal jugular vein cannulation in neurosurgical infants. Intensive Care Med 2008; 34:2100-5.

64. Schweickert WD, Herlitz J, Pohlman AS, Gehlbach BK, Hall JB, Kress JP. A randomized, controlled trial evaluating postinsertion neck ultrasound in peripherally inserted central catheter procedures. Crit Care Med 2009; 37:1217-21.

65. Clark-Christoff N, Watters VA, Sparks W, Snyder P, Grant JP. Use of triple-lumen subclavian catheters for administration of total parenteral nutrition. JPEN J Parenter Enteral Nutr 1992; 16:403-7.

66. Early TF, Gregory RT, Wheeler JR, Snyder SO Jr., Gayle RG. Increased infection rate in double-lumen versus single-lumen Hickman catheters in cancer patients. South Med J 1990; 83:34-6.

67. Hilton E, Haslett TM, Borenstein MT, Tucci V, Isenberg HD, Singer C. Central catheter infections: single- versus triple-lumen catheters. Influence of guide wires on infection rates when used for replacement of catheters. Am J Med 1988; 84:667-72.

68. Yeung C, May J, Hughes R. Infection rate for single lumen v triple lumen subclavian catheters. Infect Control Hosp Epidemiol 1988; 9:154-8.

69. Pronovost P, Needham D, Berenholtz S, et al. An intervention to decrease catheter-related bloodstream infections in the ICU. N Engl J Med 2006; 355:2725-32.

70. Berenholtz SM, Pronovost PJ, Lipsett PA, et al. Eliminating catheterrelated bloodstream infections in the intensive care unit. Crit Care Med 2004; 32:2014-20.

71. Lederle FA, Parenti CM, Berskow LC, Ellingson KJ. The idle intravenous catheter. Ann Intern Med 1992; 116:737-8. 
72. Parenti CM, Lederle FA, Impola CL, Peterson LR. Reduction of unnecessary intravenous catheter use. Internal medicine house staff participate in a successful quality improvement project. Arch Intern Med 1994; 154:1829-32.

73. Abi-Said D, Raad I, Umphrey J, et al. Infusion therapy team and dressing changes of central venous catheters. Infect Control Hosp Epidemiol 1999; 20:101-5.

74. Capdevila JA, Segarra A, Pahissa A. Catheter-related bacteremia in patients undergoing hemodialysis. Ann Intern Med 1998; 128:600.

75. Mermel LA, Maki DG. Infectious complications of Swan-Ganz pulmonary artery catheters. Pathogenesis, epidemiology, prevention, and management. Am J Respir Crit Care Med 1994; 149:1020-36.

76. Raad II, Hohn DC, Gilbreath BJ, et al. Prevention of central venous catheter-related infections by using maximal sterile barrier precautions during insertion. Infect Control Hosp Epidemiol 1994; 15:231-8.

77. Boyce JM, Pittet D. Guideline for hand hygiene in health-care settings: recommendations of the Healthcare Infection Control Practices Advisory Committee and the HICPAC/SHEA/APIC/IDSA Hand Hygiene Task Force. Infect Control Hosp Epidemiol 2002; 23:S3-40.

78. Bischoff WE, Reynolds TM, Sessler CN, Edmond MB, Wenzel RP. Handwashing compliance by health care workers: the impact of introducing an accessible, alcohol-based hand antiseptic. Arch Intern Med 2000; 160:1017-21.

79. Pittet D, Dharan S, Touveneau S, Sauvan V, Perneger TV. Bacterial contamination of the hands of hospital staff during routine patient care. Arch Intern Med 1999; 159:821-6.

80. Carrer S, Bocchi A, Bortolotti M, et al. Effect of different sterile barrier precautions and central venous catheter dressing on the skin colonization around the insertion site. Minerva Anestesiol 2005; 71:197-206.

81. Cohen Y, Fosse JP, Karoubi P, et al. The "hands-off" catheter and the prevention of systemic infections associated with pulmonary artery catheter: a prospective study. Am J Respir Crit Care Med 1998; 157:284-7.

82. Maki DG, Ringer M, Alvarado CJ. Prospective randomised trial of povidone-iodine, alcohol, and chlorhexidine for prevention of infection associated with central venous and arterial catheters. Lancet 1991; 338:339-43.

83. Mimoz O, Pieroni L, Lawrence C, et al. Prospective, randomized trial of two antiseptic solutions for prevention of central venous or arterial catheter colonization and infection in intensive care unit patients. Crit Care Med 1996; 24:1818-23.

84. Maki DG, Stolz SS, Wheeler S, Mermel LA. A prospective, randomized trial of gauze and two polyurethane dressings for site care of pulmonary artery catheters: implications for catheter management. Crit Care Med 1994; 22:1729-37.

85. Bijma R, Girbes AR, Kleijer DJ, Zwaveling JH. Preventing central venous catheter-related infection in a surgical intensive-care unit. Infect Control Hosp Epidemiol 1999; 20:618-20.

86. Madeo M, Martin CR, Turner C, Kirkby V, Thompson DR. A randomized trial comparing Arglaes (a transparent dressing containing silver ions) to Tegaderm (a transparent polyurethane dressing) for dressing peripheral arterial catheters and central vascular catheters. Intensive Crit Care Nurs 1998; 14:187-91.

87. Rasero L, Degl'Innocenti M, Mocali M, et al. Comparison of two different time interval protocols for central venous catheter dressing in bone marrow transplant patients: results of a randomized, multicenter study. The Italian Nurse Bone Marrow Transplant Group (GITMO). Haematologica 2000; 85:275-9.

88. Zakrzewska-Bode A, Muytjens HL, Liem KD, Hoogkamp-Korstanje JA. Mupirocin resistance in coagulase-negative staphylococci, after topical prophylaxis for the reduction of colonization of central venous catheters. J Hosp Infect 1995; 31:189-93.

89. Flowers RH, Schwenzer KJ, Kopel RF, Fisch MJ, Tucker SI, Farr BM. Efficacy of an attachable subcutaneous cuff for the prevention of in- travascular catheter-related infection. A randomized, controlled trial. JAMA 1989; 261:878-83.

90. Robbins J, Cromwell P, Korones DN. Swimming and central venous catheter-related infections in the child with cancer. J Pediatr Oncol Nurs 1999; 16:51-6.

91. Howell PB, Walters PE, Donowitz GR, Farr BM. Risk factors for infection of adult patients with cancer who have tunnelled central venous catheters. Cancer 1995; 75:1367-75.

92. Ivy DD, Calderbank M, Wagner BD, et al. Closed-hub systems with protected connections and the reduction of risk of catheter-related bloodstream infection in pediatric patients receiving intravenous prostanoid therapy for pulmonary hypertension. Infect Control Hosp Epidemiol 2009; 30:823-9.

93. Timsit JF, Schwebel C, Bouadma L, et al. Chlorhexidine-impregnated sponges and less frequent dressing changes for prevention of catheterrelated infections in critically ill adults: a randomized controlled trial. JAMA 2009; 301:1231-41.

94. Rao SP, Oreopoulos DG. Unusual complications of a polyurethane PD catheter. Perit Dial Int 1997; 17:410-2.

95. Riu S, Ruiz CG, Martinez-Vea A, Peralta C, Oliver JA. Spontaneous rupture of polyurethane peritoneal catheter. A possible deleterious effect of mupirocin ointment. Nephrol Dial Transplant 1998; 13:1870-1.

96. Garland JS, Alex CP, Mueller CD, et al. A randomized trial comparing povidone-iodine to a chlorhexidine gluconate-impregnated dressing for prevention of central venous catheter infections in neonates. Pediatrics 2001; 107:1431-6.

97. Ho KM, Litton E. Use of chlorhexidine-impregnated dressing to prevent vascular and epidural catheter colonization and infection: a meta-analysis. J Antimicrob Chemother 2006; 58:281-7.

98. Levy I, Katz J, Solter E, et al. Chlorhexidine-impregnated dressing for prevention of colonization of central venous catheters in infants and children: a randomized controlled study. Pediatr Infect Dis J 2005; 24:676-9.

99. Lorenzen AN, Itkin DJ. Surveillance of infection in home care. Am J Infect Control 1992; 20:326-9.

100. White MC. Infections and infection risks in home care settings. Infect Control Hosp Epidemiol 1992; 13:535-9.

101. White MC, Ragland KE. Surveillance of intravenous catheter-related infections among home care clients. Am J Infect Control 1994; 22:231-5.

102. Bleasdale SC, Trick WE, Gonzalez IM, Lyles RD, Hayden MK, Weinstein RA. Effectiveness of chlorhexidine bathing to reduce catheter-associated bloodstream infections in medical intensive care unit patients. Arch Intern Med 2007; 167:2073-9.

103. Munoz-Price LS, Hota B, Stemer A, Weinstein RA. Prevention of bloodstream infections by use of daily chlorhexidine baths for patients at a long-term acute care hospital. Infect Control Hosp Epidemiol 2009; 30:1031-5.

104. Popovich KJ, Hota B, Hayes R, Weinstein RA, Hayden MK. Effectiveness of routine patient cleansing with chlorhexidine gluconate for infection prevention in the medical intensive care unit. Infect Control Hosp Epidemiol 2009; 30:959-63.

105. Yamamoto AJ, Solomon JA, Soulen MC, et al. Sutureless securement device reduces complications of peripherally inserted central venous catheters. J Vasc Interv Radiol 2002; 13:77-81.

106. Brun-Buisson C, Doyon F, Sollet JP, Cochard JF, Cohen Y, Nitenberg G. Prevention of intravascular catheter-related infection with newer chlorhexidine-silver sulfadiazine-coated catheters: a randomized controlled trial. Intensive Care Med 2004; 30:837-43.

107. Ostendorf T, Meinhold A, Harter C, et al. Chlorhexidine and silversulfadiazine coated central venous catheters in haematological patients-a double-blind, randomised, prospective, controlled trial. Support Care Cancer 2005; 13:993-1000.

108. Rupp ME, Lisco SJ, Lipsett PA, et al. Effect of a second-generation venous catheter impregnated with chlorhexidine and silver sulfadiazine on central catheter-related infections: a randomized, controlled trial. Ann Intern Med 2005; 143:570-80. 
109. Darouiche RO, Raad II, Heard SO, et al. A comparison of two antimicrobial-impregnated central venous catheters. Catheter Study Group. N Engl J Med 1999; 340:1-8.

110. Raad I, Darouiche R, Dupuis J, et al. Central venous catheters coated with minocycline and rifampin for the prevention of catheter-related colonization and bloodstream infections. A randomized, doubleblind trial. The Texas Medical Center Catheter Study Group. Ann Intern Med 1997; 127:267-74.

111. Hanna H, Benjamin R, Chatzinikolaou I, et al. Long-term silicone central venous catheters impregnated with minocycline and rifampin decrease rates of catheter-related bloodstream infection in cancer patients: a prospective randomized clinical trial. J Clin Oncol 2004; 22:3163-71.

112. Bhutta A, Gilliam C, Honeycutt M, et al. Reduction of bloodstream infections associated with catheters in paediatric intensive care unit: stepwise approach. BMJ 2007; 334:362-5.

113. Chelliah A, Heydon KH, Zaoutis TE, et al. Observational trial of antibiotic-coated central venous catheters in critically ill pediatric patients. Pediatr Infect Dis J 2007; 26:816-20.

114. van de Wetering MD, van Woensel JBM. Prophylactic antibiotics for preventing early central venous catheter Gram positive infections in oncology patients. Cochrane Database of Systematic Reviews 2007; Issue 1. Art. No.: CD003295. DOI: 10.1002/ 14651858.CD003295.pub2.

115. Maki DG, Band JD. A comparative study of polyantibiotic and iodophorointments in prevention of vascular catheter-related infection. Am J Med 1981; 70:739-44.

116. Fukunaga A, Naritaka H, Fukaya R, Tabuse M, Nakamura T. Povidoneiodine ointment and gauze dressings associated with reduced catheterrelated infection in seriously ill neurosurgical patients. Infect Control Hosp Epidemiol 2004; 25:696-8.

117. Johnson DW, MacGinley R, Kay TD, et al. A randomized controlled trial of topical exit site mupirocin application in patients with tunnelled, cuffed haemodialysis catheters. Nephrol Dial Transplant 2002; 17:1802-7.

118. Fong IW. Prevention of haemodialysis and peritoneal dialysis catheter related infection by topical povidone-iodine. Postgrad Med J 1993; 69(Suppl 3):S15-7.

119. Levin A, Mason AJ, Jindal KK, Fong IW, Goldstein MB. Prevention of hemodialysis subclavian vein catheter infections by topical povidoneiodine. Kidney Int 1991; 40:934-8.

120. Schwartz C, Henrickson KJ, Roghmann K, Powell K. Prevention of bacteremia attributed to luminal colonization of tunneled central venous catheters with vancomycin-susceptible organisms. J Clin Oncol 1990; 8:1591-7.

121. Rackoff WR, Weiman M, Jakobowski D, et al. A randomized, controlled trial of the efficacy of a heparin and vancomycin solution in preventing central venous catheter infections in children. J Pediatr 1995; 127:147-51.

122. Carratala J, Niubo J, Fernandez-Sevilla A, et al. Randomized, double-blind trial of an antibiotic-lock technique for prevention of gram-positive central venous catheter-related infection in neutropenic patients with cancer. Antimicrob Agents Chemother 1999; 43:2200-4.

123. Jurewitsch B, Lee T, Park J, Jeejeebhoy K. Taurolidine $2 \%$ as an antimicrobial lock solution for prevention of recurrent catheter-related bloodstream infections. J Parenter Enteral Nutr 1998; 22:242-4.

124. Henrickson KJ, Axtell RA, Hoover SM, et al. Prevention of central venous catheter-related infections and thrombotic events in immunocompromised children by the use of vancomycin/ciprofloxacin/ heparin flush solution: a randomized, multicenter, double-blind trial. J Clin Oncol 2000; 18:1269-78.

125. Garland JS, Alex CP, Henrickson KJ, McAuliffe TL, Maki DG. A vancomycin-heparin lock solution for prevention of nosocomial bloodstream infection in critically ill neonates with peripherally inserted central venous catheters: a prospective, randomized trial. Pediatrics 2005; 116:e198-205.
126. Daghistani D, Horn M, Rodriguez Z, Schoenike S, Toledano S. Prevention of indwelling central venous catheter sepsis. Med Pediatr Oncol 1996; 26:405-8.

127. Barriga FJ, Varas M, Potin M, et al. Efficacy of a vancomycin solution to prevent bacteremia associated with an indwelling central venous catheter in neutropenic and non-neutropenic cancer patients. Med Pediatr Oncol 1997; 28:196-200.

128. Dogra GK, Herson H, Hutchison B, et al. Prevention of tunneled hemodialysis catheter-related infections using catheter-restricted filling with gentamicin and citrate: a randomized controlled study. J Am Soc Nephrol 2002; 13:2133-9.

129. Allon M. Prophylaxis against dialysis catheter-related bacteremia with a novel antimicrobial lock solution. Clin Infect Dis 2003; 36: 1539-44.

130. Elhassan NO, Stevens TP, Gigliotti F, Hardy DJ, Cole CA, Sinkin RA. Vancomycin usage in central venous catheters in a neonatal intensive care unit. Pediatr Infect Dis J 2004; 23:201-6.

131. McIntyre CW, Hulme LJ, Taal M, Fluck RJ. Locking of tunneled hemodialysis catheters with gentamicin and heparin. Kidney Int 2004; 66:801-5.

132. Betjes MG, van Agteren M. Prevention of dialysis catheter-related sepsis with a citrate-taurolidine-containing lock solution. Nephrol Dial Transplant 2004; 19:1546-1.

133. Weijmer MC, van den Dorpel MA, Van de Ven PJ, et al. Randomized, clinical trial comparison of trisodium citrate $30 \%$ and heparin as catheter-locking solution in hemodialysis patients. J Am Soc Nephrol 2005; 16:2769-77.

134. Bleyer AJ, Mason L, Russell G, Raad II, Sherertz RJ. A randomized, controlled trial of a new vascular catheter flush solution (minocyclineEDTA) in temporary hemodialysis access. Infect Control Hosp Epidemiol 2005; 26:520-4.

135. Kim SH, Song KI, Chang JW, et al. Prevention of uncuffed hemodialysis catheter-related bacteremia using an antibiotic lock technique: a prospective, randomized clinical trial. Kidney Int 2006; 69:161-4.

136. Al-Hwiesh AK, Abdul-Rahman IS. Successful prevention of tunneled, central catheter infection by antibiotic lock therapy using vancomycin and gentamycin. Saudi J Kidney Dis Transpl 2007; 18:239-47.

137. Nori US, Manoharan A, Yee J, Besarab A. Comparison of low-dose gentamicin with minocycline as catheter lock solutions in the prevention of catheter-related bacteremia. Am J Kidney Dis 2006; 48:596-605.

138. Saxena AK, Panhotra BR, Sundaram DS, et al. Tunneled catheters' outcome optimization among diabetics on dialysis through antibiotic-lock placement. Kidney Int 2006; 70:1629-35.

139. Randolph AG, Cook DJ, Gonzales CA, Andrew M. Benefit of heparin in central venous and pulmonary artery catheters: a meta-analysis of randomized controlled trials. Chest 1998; 113:165-71.

140. Tager IB, Ginsberg MB, Ellis SE, et al. An epidemiologic study of the risks associated with peripheral intravenous catheters. Am J Epidemiol 1983; 118:839-51.

141. Lai KK. Safety of prolonging peripheral cannula and i.v. tubing use from 72 hours to 96 hours. Am J Infect Control 1998; 26:66-70.

142. Van Donk P, Rickard CM, McGrail MR, Doolan G. Routine replacement versus clinical monitoring of peripheral intravenous catheters in a regional hospital in the home program: a randomized controlled trial. Infect Control Hosp Epidemiol 2009; 30:915-7.

143. Webster J, Clarke S, Paterson D, et al. Routine care of peripheral intravenous catheters versus clinically indicated replacement: randomised controlled trial. BMJ 2008; 337:a339.

144. Webster J, Osborne S, Rickard C, Hall J. Clinically-indicated replacement versus routine replacement of peripheral venous catheters. Cochrane Database Syst Rev 2010; 3:CD007798.

145. Boo NY, Wong NC, Zulkifli SS, Lye MS. Risk factors associated with umbilical vascular catheter-associated thrombosis in newborn infants. J Paediatr Child Health 1999; 35:460-5. 
146. Garland JS, Buck RK, Maloney P, et al. Comparison of $10 \%$ povidoneiodine and $0.5 \%$ chlorhexidine gluconate for the prevention of peripheral intravenous catheter colonization in neonates: a prospective trial. Pediatr Infect Dis J 1995; 14:510-6.

147. Krauss AN, Albert RF, Kannan MM. Contamination of umbilical catheters in the newborn infant. J Pediatr 1970; 77:965-9.

148. Landers S, Moise AA, Fraley JK, Smith EO, Baker CJ. Factors associated with umbilical catheter-related sepsis in neonates. Am J Dis Child 1991; 145:675-80.

149. Cronin WA, Germanson TP, Donowitz LG. Intravascular catheter colonization and related bloodstream infection in critically ill neonates. Infect Control Hosp Epidemiol 1990; 11:301-8.

150. Miller KL, Coen PE, White WJ, Hurst WJ, Achey BE, Lang CM. Effectiveness of skin absorption of tincture of I in blocking radioiodine from the human thyroid gland. Health Phys 1989; 56:911-4.

151. Ankola PA, Atakent YS. Effect of adding heparin in very low concentration to the infusate to prolong the patency of umbilical artery catheters. Am J Perinatol 1993; 10:229-32.

152. David RJ, Merten DF, Anderson JC, Gross S. Prevention of umbilical artery catheter clots with heparinized infusates. Dev Pharmacol Ther $1981 ; 2: 117-26$.

153. Horgan MJ, Bartoletti A, Polansky S, Peters JC, Manning TJ, Lamont BM. Effect of heparin infusates in umbilical arterial catheters on frequency of thrombotic complications. J Pediatr 1987; 111:774-8.

154. Fletcher MA, Brown DR, Landers S, Seguin J. Umbilical arterial catheter use: report of an audit conducted by the Study Group for Complications of Perinatal Care. Am J Perinatol 1994; 11:94-9.

155. Seguin J, Fletcher MA, Landers S, Brown D, Macpherson T. Umbilical venous catheterizations: audit by the Study Group for Complications of Perinatal Care. Am J Perinatol 1994; 11:67-70.

156. Loisel DB, Smith MM, MacDonald MG, Martin GR. Intravenous access in newborn infants: impact of extended umbilical venous catheter use on requirement for peripheral venous lines. J Perinatol 1996; 16:461-6.

157. Martin C, Saux P, Papazian L, Gouin F. Long-term arterial cannulation in ICU patients using the radial artery or dorsalis pedis artery. Chest 2001; 119:901-6.

158. Koh DB, Gowardman JR, Rickard CM, Robertson IK, Brown A. Prospective study of peripheral arterial catheter infection and comparison with concurrently sited central venous catheters. Crit Care Med 2008; 36:397-402.

159. Rijnders BJ, Van Wijngaerden E, Wilmer A, Peetermans WE. Use of full sterile barrier precautions during insertion of arterial catheters: a randomized trial. Clin Infect Dis 2003; 36:743-8.

160. Donowitz LG, Marsik FJ, Hoyt JW, Wenzel RP. Serratia marcescens bacteremia from contaminated pressure transducers. JAMA 1979; 242:1749-51.

161. Luskin RL, Weinstein RA, Nathan C, Chamberlin WH, Kabins SA. Extended use of disposable pressure transducers. A bacteriologic evaluation. JAMA 1986; 255:916-20.

162. Maki DG, Hassemer CA. Endemic rate of fluid contamination and related septicemia in arterial pressure monitoring. Am J Med 1981; 70:733-8.

163. Mermel LA, Maki DG. Epidemic bloodstream infections from hemodynamic pressure monitoring: signs of the times. Infect Control Hosp Epidemiol 1989; 10:47-53.

164. Tenold R, Priano L, Kim K, Rourke B, Marrone T. Infection potential of nondisposable pressure transducers prepared prior to use. Crit Care Med 1987; 15:582-3.

165. Eyer S, Brummitt C, Crossley K, Siegel R, Cerra F. Catheter-related sepsis: prospective, randomized study of three methods of long-term catheter maintenance. Crit Care Med 1990; 18:1073-9.

166. Raad I, Umphrey J, Khan A, Truett LJ, Bodey GP. The duration of placement as a predictor of peripheral and pulmonary arterial catheter infections. J Hosp Infect 1993; 23:17-26.
167. Thomas F, Burke JP, Parker J, et al. The risk of infection related to radial vs femoral sites for arterial catheterization. Crit Care Med 1983; 11:807-12.

168. Leroy O, Billiau V, Beuscart C, et al. Nosocomial infections associated with long-term radial artery cannulation. Intensive Care Med 1989; 15:241-6.

169. Fisher MC, Long SS, Roberts EM, Dunn JM, Balsara RK. Pseudomonas maltophilia bacteremia in children undergoing open heart surgery. JAMA $1981 ; 246: 1571-4$.

170. Stamm WE, Colella JJ, Anderson RL, Dixon RE. Indwelling arterial catheters as a source of nosocomial bacteremia. An outbreak caused by Flavobacterium Species. N Engl J Med 1975; 292:1099-102.

171. Weinstein RA, Emori TG, Anderson RL, Stamm WE. Pressure transducers as a source of bacteremia after open heart surgery. Report of an outbreak and guidelines for prevention. Chest 1976; 69:338-44.

172. Shinozaki T, Deane RS, Mazuzan JE Jr., Hamel AJ, Hazelton D. Bacterial contamination of arterial lines. A prospective study. JAMA 1983; 249:223-5.

173. Solomon SL, Alexander H, Eley JW, et al. Nosocomial fungemia in neonates associated with intravascular pressure-monitoring devices. Pediatr Infect Dis 1986; 5:680-5.

174. Weems JJ Jr., Chamberland ME, Ward J, Willy M, Padhye AA, Solomon SL. Candida parapsilosis fungemia associated with parenteral nutrition and contaminated blood pressure transducers. J Clin Microbiol 1987; 25:1029-32.

175. Villarino ME, Jarvis WR, O'Hara C, Bresnahan J, Clark N. Epidemic of Serratia marcescens bacteremia in a cardiac intensive care unit. J Clin Microbiol 1989; 27:2433-6.

176. Beck-Sague CM, Jarvis WR, Brook JH, et al. Epidemic bacteremia due to Acinetobacter baumannii in five intensive care units. Am J Epidemiol 1990; 132:723-33.

177. Gillies D, Wallen MM, Morrison AL, Rankin K, Nagy SA, O’Riordan E. Optimal timing for intravenous administration set replacement. Cochrane Database of Systematic Reviews 2005; Issue 4. Art. No.: CD003588. DOI: 10.1002/14651858.CD003588.pub2.

178. Sitges-Serra A, Linares J, Perez JL, Jaurrieta E, Lorente L. A randomized trial on the effect of tubing changes on hub contamination and catheter sepsis during parenteral nutrition. JPEN J Parenter Enteral Nutr 1985; 9:322-5.

179. Snydman DR, Donnelly-Reidy M, Perry LK, Martin WJ. Intravenous tubing containing burettes can be safely changed at 72 hour intervals. Infect Control 1987; 8:113-6.

180. Maki DG, Botticelli JT, LeRoy ML, Thielke TS. Prospective study of replacing administration sets for intravenous therapy at 48 - vs 72 -hour intervals. 72 hours is safe and cost-effective. JAMA 1987; 258:1777-81.

181. Josephson A, Gombert ME, Sierra MF, Karanfil LV, Tansino GF. The relationship between intravenous fluid contamination and the frequency of tubing replacement. Infect Control 1985; 6:367-70.

182. Melly MA, Meng HC, Schaffner W. Microbiol growth in lipid emulsions used in parenteral nutrition. Arch Surg 1975; 110:1479-81.

183. Mershon J, Nogami W, Williams JM, Yoder C, Eitzen HE, Lemons JA. Bacterial/fungal growth in a combined parenteral nutrition solution. JPEN J Parenter Enteral Nutr 1986; 10:498-502.

184. Gilbert M, Gallagher SC, Eads M, Elmore MF. Microbial growth patterns in a total parenteral nutrition formulation containing lipid emulsion. JPEN J Parenter Enteral Nutr 1986; 10:494-7.

185. Maki DG, Martin WT. Nationwide epidemic of septicemia caused by contaminated infusion products. IV. Growth of microbial pathogens in fluids for intravenous infusions. J Infect Dis 1975; 131:267-72.

186. Bennett SN, McNeil MM, Bland LA, et al. Postoperative infections traced to contamination of an intravenous anesthetic, propofol. N Engl J Med 1995; 333:147-54.

187. Arduino MJ, Bland LA, Danzig LE, McAllister SK, Aguero SM. Microbiologic evaluation of needleless and needle-access devices. Am J Infect Control 1997; 25:377-80. 
188. Brown JD, Moss HA, Elliott TS. The potential for catheter microbial contamination from a needleless connector. J Hosp Infect 1997; 36:181-9.

189. Cookson ST, Ihrig M, O’Mara EM, et al. Increased bloodstream infection rates in surgical patients associated with variation from recommended use and care following implementation of a needleless device. Infect Control Hosp Epidemiol 1998; 19:23-7.

190. Seymour VM, Dhallu TS, Moss HA, Tebbs SE, Elliot TS. A prospective clinical study to investigate the microbial contamination of a needleless connector. J Hosp Infect 2000; 45:165-8.

191. Luebke MA, Arduino MJ, Duda DL, et al. Comparison of the microbial barrier properties of a needleless and a conventional needlebased intravenous access system. Am J Infect Control 1998; 26:437-41.

192. McDonald LC, Banerjee SN, Jarvis WR. Line-associated bloodstream infections in pediatric intensive-care-unit patients associated with a needleless device and intermittent intravenous therapy. Infect Control Hosp Epidemiol 1998; 19:772-7.

193. Mendelson MH, Short LJ, Schechter CB, et al. Study of a needleless intermittent intravenous-access system for peripheral infusions: analysis of staff, patient, and institutional outcomes. Infect Control Hosp Epidemiol 1998; 19:401-6.

194. Do AN, Ray BJ, Banerjee SN, et al. Bloodstream infection associated with needleless device use and the importance of infectioncontrol practices in the home health care setting. J Infect Dis 1999; 179:442-8.

195. Soothill JS, Bravery K, Ho A, Macqueen S, Collins J, Lock P. A fall in bloodstream infections followed a change to $2 \%$ chlorhexidine in $70 \%$ isopropanol for catheter connection antisepsis: a pediatric single center before/after study on a hemopoietic stem cell transplant ward. Am J Infect Control 2009; 37:626-30.

196. Casey AL, Burnell S, Whinn H, Worthington T, Faroqui MH, Elliott TS. A prospective clinical trial to evaluate the microbial barrier of a needleless connector. J Hosp Infect 2007; 65:212-8.

197. Rupp ME, Sholtz LA, Jourdan DR, et al. Outbreak of bloodstream infection temporally associated with the use of an intravascular needleless valve. Clin Infect Dis 2007; 44:1408-14.

198. Salgado CD, Chinnes L, Paczesny TH, Cantey JR. Increased rate of catheter-related bloodstream infection associated with use of a needleless mechanical valve device at a long-term acute care hospital. Infect Control Hosp Epidemiol 2007; 28:684-8.

199. Maragakis LL, Bradley KL, Song X, et al. Increased catheter-related bloodstream infection rates after the introduction of a new mechanical valve intravenous access port. Infect Control Hosp Epidemiol 2006; 27:67-70.

200. Field K, McFarlane C, Cheng AC, et al. Incidence of catheter-related bloodstream infection among patients with a needleless, mechanical valve-based intravenous connector in an Australian hematology-oncology unit. Infect Control Hosp Epidemiol 2007; 28:610-3.

201. Costello JM, Morrow DF, Graham DA, Potter-Bynoe G, Sandora TJ, Laussen PC. Systematic intervention to reduce central line-associated bloodstream infection rates in a pediatric cardiac intensive care unit. Pediatrics 2008; 121:915-23.

202. Frankel HL, Crede WB, Topal JE, Roumanis SA, Devlin MW, Foley AB. Use of corporate Six Sigma performance-improvement strategies to reduce incidence of catheter-related bloodstream infections in a surgical ICU. J Am Coll Surg 2005; 201:349-58.

203. Galpern D, Guerrero A, Tu A, Fahoum B, Wise L. Effectiveness of a central line bundle campaign on line-associated infections in the intensive care unit. Surgery 2008; 144:492-5; discussion 495.

204. McKee C, Berkowitz I, Cosgrove SE, et al. Reduction of catheterassociated bloodstream infections in pediatric patients: experimentation and reality. Pediatr Crit Care Med 2008; 9:40-6.

205. Pronovost PJ, Berenholtz SM, Goeschel CA. Improving the quality of measurement and evaluation in quality improvement efforts. Am J Med Qual 2008; 23:143-6.
206. Horan TC, Andrus M, Dudeck MA. CDC/NHSN surveillance definition of health care-associated infection and criteria for specific types of infections in the acute care setting. Am J Infect Control 2008; 36:309-32.

207. Edwards JR, Peterson KD, Mu Y, et al. National Healthcare Safety Network (NHSN) report: data summary for 2006 through 2008, issued December 2009. Am J Infect Control 2009; 37:783-805.

208. Wisplinghoff $H$, Bischoff $T$, Tallent SM, Seifert H, Wenzel RP, Edmond MB. Nosocomial bloodstream infections in US hospitals: analysis of 24,179 cases from a prospective nationwide surveillance study. Clin Infect Dis 2004; 39:309-17.

209. Gaynes R, Edwards JR. Overview of nosocomial infections caused by gram-negative bacilli. Clin Infect Dis 2005; 41:848-54.

210. Burton DC, Edwards JR, Horan TC, Jernigan JA, Fridkin SK. Methicillin-resistant Staphylococcus aureus central line-associated bloodstream infections in US intensive care units, 1997-2007. JAMA 2009; 301:727-36.

211. Safdar N, Maki DG. The pathogenesis of catheter-related bloodstream infection with noncuffed short-term central venous catheters. Intensive Care Med 2004; 30:62-7.

212. Maki DG, Weise CE, Sarafin HW. A semiquantitative culture method for identifying intravenous-catheter-related infection. N Engl J Med 1977; 296:1305-9.

213. Raad I, Costerton W, Sabharwal U, Sacilowski M, Anaissie E, Bodey GP. Ultrastructural analysis of indwelling vascular catheters: a quantitative relationship between luminal colonization and duration of placement. J Infect Dis 1993; 168:400-7.

214. Dobbins BM, Kite P, Kindon A, McMahon MJ, Wilcox MH. DNA fingerprinting analysis of coagulase negative staphylococci implicated in catheter related bloodstream infections. J Clin Pathol 2002; 55:824-8.

215. Anaissie E, Samonis G, Kontoyiannis D, et al. Role of catheter colonization and infrequent hematogenous seeding in catheter-related infections. Eur J Clin Microbiol Infect Dis 1995; 14:134-7.

216. Raad I, Hanna HA, Awad A, et al. Optimal frequency of changing intravenous administration sets: is it safe to prolong use beyond 72 hours? Infect Control Hosp Epidemiol 2001; 22:136-9.

217. Mehall JR, Saltzman DA, Jackson RJ, Smith SD. Fibrin sheath enhances central venous catheter infection. Crit Care Med 2002; 30:908-12.

218. Donlan RM, Costerton JW. Biofilms: survival mechanisms of clinically relevant microorganisms. Clin Microbiol Rev 2002; 15:167-93.

219. Hawser SP, Douglas LJ. Biofilm formation by Candida species on the surface of catheter materials in vitro. Infect Immun 1994; 62:915-21.

220. Stillman RM, Soliman F, Garcia L, Sawyer PN. Etiology of catheterassociated sepsis. Correlation with thrombogenicity. Arch Surg 1977; 112:1497-9.

221. Raad II, Luna M, Khalil SA, Costerton JW, Lam C, Bodey GP. The relationship between the thrombotic and infectious complications of central venous catheters. JAMA 1994; 271:1014-6.

222. Herrmann M, Suchard SJ, Boxer LA, Waldvogel FA, Lew PD. Thrombospondin binds to Staphylococcus aureus and promotes staphylococcal adherence to surfaces. Infect Immun 1991; 59:279-88.

223. Shanks RM, Sargent JL, Martinez RM, Graber ML, O’Toole GA. Catheter lock solutions influence staphylococcal biofilm formation on abiotic surfaces. Nephrol Dial Transplant 2006; 21:2247-55.

224. Chatzinikolaou I, Zipf TF, Hanna H, et al. Minocycline-ethylenediaminetetraacetate lock solution for the prevention of implantable port infections in children with cancer. Clin Infect Dis 2003; 36:116-9.

225. McDevitt D, Francois P, Vaudaux P, Foster TJ. Identification of the ligand-binding domain of the surface-located fibrinogen receptor (clumping factor) of Staphylococcus aureus. Mol Microbiol 1995; 16:895-907.

226. Ni Eidhin D, Perkins S, Francois P, Vaudaux P, Hook M, Foster TJ. Clumping factor B (ClfB), a new surface-located fibrinogen-binding adhesin of Staphylococcus aureus. Mol Microbiol 1998; 30:245-57.

227. Mack D, Davies AP, Harris LG, Rohde H, Horstkotte MA, Knobloch JK. Microbial interactions in Staphylococcus epidermidis biofilms. Anal Bioanal Chem 2007; 387:399-408. 
228. von Eiff C, Peters G, Heilmann C. Pathogenesis of infections due to coagulase-negative staphylococci. Lancet Infect Dis 2002; 2:677-85.

229. Zhu Y, Weiss EC, Otto M, Fey PD, Smeltzer MS, Somerville GA. Staphylococcus aureus metabolism in a biofilm: the influence of arginine on polysaccharide intercellular adhesin synthesis, biofilm formation, and pathogenesis. Infect Immun 2007; 75:4219-26.

230. Murga R, Miller JM, Donlan RM. Biofilm formation by gram-negative bacteria on central venous catheter connectors: effect of conditioning films in a laboratory model. J Clin Microbiol 2001; 39:2294-7.

231. Douglas LJ. Candida biofilms and their role in infection. Trends Microbiol 2003; 11:30-6.

232. Donlan RM. Biofilms: microbial life on surfaces. Emerg Infect Dis 2002; 8:881-90

233. Dunne WM Jr., Burd EM. The effects of magnesium, calcium, EDTA, and $\mathrm{pH}$ on the in vitro adhesion of Staphylococcus epidermidis to plastic. Microbiol Immunol 1992; 36:1019-27.

234. Ozerdem Akpolat N, Elci S, Atmaca S, Akbayin H, Gul K. The effects of magnesium, calcium and EDTA on slime production by Staphylococcus epidermidis strains. Folia Microbiol (Praha) 2003; 48:649-53.

235. Banin E, Brady KM, Greenberg EP. Chelator-induced dispersal and killing of Pseudomonas aeruginosa cells in a biofilm. Appl Environ Microbiol 2006; 72:2064-9.

236. Donlan RM. Role of biofilms in antimicrobial resistance. ASAIO J 2000; 46:S47-52.

237. Farber BF, Kaplan MH, Clogston AG. Staphylococcus epidermidis extracted slime inhibits the antimicrobial action of glycopeptide antibiotics. J Infect Dis 1990; 161:37-40.

238. Branchini ML, Pfaller MA, Rhine-Chalberg J, Frempong T, Isenberg HD. Genotypic variation and slime production among blood and catheter isolates of Candida parapsilosis. J Clin Microbiol 1994; 32:452-6.

239. Sanders RA, Sheldon GF. Septic complications of total parenteral nutrition. A five year experience. Am J Surg 1976; 132:214-20.

240. Ryan JA Jr., Abel RM, Abbott WM, et al. Catheter complications in total parenteral nutrition. A prospective study of 200 consecutive patients. N Engl J Med 1974; 290:757-61.

241. Murphy LM, Lipman TO. Central venous catheter care in parenteral nutrition: a review. JPEN J Parenter Enteral Nutr 1987; 11:190-201.

242. Armstrong CW, Mayhall CG, Miller KB, et al. Prospective study of catheter replacement and other risk factors for infection of hyperalimentation catheters. J Infect Dis 1986; 154:808-16.

243. Garland JS, Dunne WM Jr., Havens P, et al. Peripheral intravenous catheter complications in critically ill children: a prospective study. Pediatrics 1992; 89:1145-50.

244. Garland JS, Nelson DB, Cheah TE, Hennes HH, Johnson TM. Infectious complications during peripheral intravenous therapy with Teflon catheters: a prospective study. Pediatr Infect Dis J 1987; 6:918-21.

245. Breschan C, Platzer M, Jost R, Schaumberger F, Stettner H, Likar R. Comparison of catheter-related infection and tip colonization between internal jugular and subclavian central venous catheters in surgical neonates. Anesthesiology 2007; 107:946-53.

246. Deshpande KS, Hatem C, Ulrich HL, et al. The incidence of infectious complications of central venous catheters at the subclavian, internal jugular, and femoral sites in an intensive care unit population. Crit Care Med 2005; 33:13-20; discussion 234-5.

247. Durbec O, Viviand X, Potie F, Vialet R, Albanese J, Martin C. A prospective evaluation of the use of femoral venous catheters in critically ill adults. Crit Care Med 1997; 25:1986-9.

248. Venkataraman ST, Thompson AE, Orr RA. Femoral vascular catheterization in critically ill infants and children. Clin Pediatr (Phila) 1997; 36:311-9.

249. Sheridan RL, Weber JM. Mechanical and infectious complications of central venous cannulation in children: lessons learned from a 10-year experience placing more than 1000 catheters. J Burn Care Res 2006; 27:713-8.
250. Stenzel JP, Green TP, Fuhrman BP, Carlson PE, Marchessault RP. Percutaneous central venous catheterization in a pediatric intensive care unit: a survival analysis of complications. Crit Care Med 1989; 17:984-8.

251. Goldstein AM, Weber JM, Sheridan RL. Femoral venous access is safe in burned children: an analysis of 224 catheters. J Pediatr 1997; 130:442-6.

252. Ramos GE, Bolgiani AN, Patino O, et al. Catheter infection risk related to the distance between insertion site and burned area. J Burn Care Rehabil 2002; 23:266-71.

253. Sheth NK, Franson TR, Rose HD, Buckmire FL, Cooper JA, Sohnle PG. Colonization of bacteria on polyvinyl chloride and Teflon intravascular catheters in hospitalized patients. J Clin Microbiol 1983; 18:1061-3.

254. Maki DG, Ringer M. Evaluation of dressing regimens for prevention of infection with peripheral intravenous catheters. Gauze, a transparent polyurethane dressing, and an iodophor-transparent dressing. JAMA 1987; 258:2396-403.

255. Pittet D, Hugonnet S, Harbath S, et al. Effectiveness of a hospital-wide prgramme to improve compliance with hand hygiene. Lancet 2000; 356:1307-9.

256. Humar A, Ostromecki A, Direnfeld J, et al. Prospective randomized trial of $10 \%$ povidone-iodine versus $0.5 \%$ tincture of chlorhexidine as cutaneous antisepsis for prevention of central venous catheter infection. Clin Infect Dis 2000; 31:1001-7.

257. Chaiyakunapruk N, Veenstra DL, Lipsky BA, Saint S. Chlorhexidine compared with povidone-iodine solution for vascular catheter-site care: a meta-analysis. Ann Intern Med 2002; 136:792-801.

258. Chaiyakunapruk N, Veenstra DL, Lipsky BA, Sullivan SD, Saint S. Vascular catheter site care: the clinical and economic benefits of chlorhexidine gluconate compared with povidone iodine. Clin Infect Dis 2003 ; $37: 764-71$.

259. Parienti JJ, du Cheyron D, Ramakers M, et al. Alcoholic povidoneiodine to prevent central venous catheter colonization: a randomized unit-crossover study. Crit Care Med 2004; 32:708-13.

260. Hoffmann KK, Weber DJ, Samsa GP, Rutala WA. Transparent polyurethane film as an intravenous catheter dressing. A meta-analysis of the infection risks. JAMA 1992; 267:2072-6.

261. Gillies D, O'Riordan E, Carr D, O'Brien I, Frost J, Gunning R. Central venous catheter dressings: a systematic review. J Adv Nurs 2003; 44:623-32.

262. Ruschulte H, Franke M, Gastmeier P, et al. Prevention of central venous catheter related infections with chlorhexidine gluconate impregnated wound dressings: a randomized controlled trial. Ann Hematol 2009; 88:267-72.

263. Veenstra DL, Saint S, Saha S, Lumley T, Sullivan SD. Efficacy of antiseptic-impregnated central venous catheters in preventing catheter-related bloodstream infection: a meta-analysis. JAMA 1999; 281:261-7.

264. Maki DG, Stolz SM, Wheeler S, Mermel LA. Prevention of central venous catheter-related bloodstream infection by use of an antisepticimpregnated catheter. A randomized, controlled trial. Ann Intern Med 1997; 127:257-66.

265. Bassetti S, Hu J, D’Agostino RB Jr., and Sherertz RJ. Prolonged antimicrobial activity of a catheter containing chlorhexidine-silver sulfadiazine extends protection against catheter infections in vivo. Antimicrob Agents Chemother 2001; 45:1535-8.

266. Oda T, Hamasaki J, Kanda N, Mikami K. Anaphylactic shock induced by an antiseptic-coated central venous [correction of nervous] catheter. Anesthesiology 1997; 87:1242-4.

267. Pittaway A, Ford S. Allergy to chlorhexidine-coated central venous catheters revisited. Br J Anaesth 2002; 88:304-5; author reply 305.

268. Stephens R, Mythen M, Kallis P, Davies DW, Egner W, Rickards A. Two episodes of life-threatening anaphylaxis in the same patient to a chlorhexidine-sulphadiazine-coated central venous catheter. $\mathrm{Br} \mathrm{J}$ Anaesth 2001; 87:306-8. 
269. Terazawa E, Shimonaka H, Nagase K, Masue T, Dohi S. Severe anaphylactic reaction due to a chlorhexidine-impregnated central venous catheter. Anesthesiology 1998; 89:1296-8.

270. Jee R, Nel L, Gnanakumaran G, Williams A, Eren E. Four cases of anaphylaxis to chlorhexidine impregnated central venous catheters: a case cluster or the tip of the iceberg? Br J Anaesth 2009; 103:614-5.

271. Veenstra DL, Saint S, Sullivan SD. Cost-effectiveness of antisepticimpregnated central venous catheters for the prevention of catheterrelated bloodstream infection. JAMA 1999; 282:554-60.

272. Tambe SM, Sampath L, Modak SM. In vitro evaluation of the risk of developing bacterial resistance to antiseptics and antibiotics used in medical devices. J Antimicrob Chemother 2001; 47:589-98.

273. Sampath LA, Tambe SM, Modak SM. In vitro and in vivo efficacy of catheters impregnated with antiseptics or antibiotics: evaluation of the risk of bacterial resistance to the antimicrobials in the catheters. Infect Control Hosp Epidemiol 2001; 22:640-6.

274. Marciante KD, Veenstra DL, Lipsky BA, Saint S. Which antimicrobial impregnated central venous catheter should we use? Modeling the costs and outcomes of antimicrobial catheter use. Am J Infect Control 2003; 31:1-8.

275. Shorr AF, Humphreys CW, Helman DL. New choices for central venous catheters: potential financial implications. Chest 2003; 124:275-84.

276. Hagau N, Studnicska D, Gavrus RL, Csipak G, Hagau R, Slavcovici AV. Central venous catheter colonization and catheter-related bloodstream infections in critically ill patients: a comparison between standard and silver-integrated catheters. Eur J Anaesthesiol 2009; 26:752-8.

277. Bong JJ, Kite P, Wilco MH, McMahon MJ. Prevention of catheter related bloodstream infection by silver iontophoretic central venous catheters: a randomised controlled trial. J Clin Pathol 2003; 56:731-5.

278. Corral L, Nolla-Salas M, Ibanez-Nolla J, et al. A prospective, randomized study in critically ill patients using the Oligon Vantex catheter. J Hosp Infect 2003; 55:212-9.

279. Ranucci M, Isgro G, Giomarelli PP, et al. Impact of oligon central venous catheters on catheter colonization and catheter-related bloodstream infection. Crit Care Med 2003; 31:52-9.

280. Raad II, Hachem RY, Abi-Said D, et al. A prospective crossover randomized trial of novobiocin and rifampin prophylaxis for the prevention of intravascular catheter infections in cancer patients treated with interleukin-2. Cancer 1998; 82:403-11.

281. McKee R, Dunsmuir R, Whitby M, Garden OJ. Does antibiotic prophylaxis at the time of catheter insertion reduce the incidence of catheter-related sepsis in intravenous nutrition? J Hosp Infect 1985; 6:419-25.

282. Sandoe JA, Kumar B, Stoddart B, et al. Effect of extended perioperative antibiotic prophylaxis on intravascular catheter colonization and infection in cardiothoracic surgery patients. J Antimicrob Chemother 2003; 52:877-9.

283. Inglis GDT, Jardine LA, Davies MW. Prophylactic antibiotics to reduce morbidity and mortality in neonates with umbilical artery catheters. Cochrane Database of Systematic Reviews 2007; Issue 4. Art. No.: CD004697. DOI: 10.1002/14651858.CD004697.pub3.

284. Craft AP, Finer N, Barrington KJ. Vancomycin for prophylaxis against sepsis in preterm neonates. Cochrane Database of Systematic Reviews 2000; Issue 1. Art. No.: CD001971. DOI: 10.1002/14651858. CD001971.

285. Norden CW. Application of antibiotic ointment to the site of venous catheterization-a controlled trial. J Infect Dis 1969; 120:611-5.

286. Zinner SH, Denny-Brown BC, Braun P, Burke JP, Toala P, Kass EH. Risk of infection with intravenous indwelling catheters: effect of application of antibiotic ointment. J Infect Dis 1969; 120:616-9.

287. von Eiff C, Becker K, Machka K, Stammer H, Peters G. Nasal carriage as a source of Staphylococcus aureus bacteremia. N Engl J Med 2001; 344:11-6.

288. Chow JW, Yu VL. Staphylococcus aureus nasal carriage in hemodialysis patients. Its role in infection and approaches to prophylaxis. Arch Intern Med 1989; 149:1258-62.
289. Yu VL, Goetz A, Wagener M, et al. Staphylococcus aureus nasal carriage and infection in patients on hemodialysis. Efficacy of antibiotic prophylaxis. N Engl J Med 1986; 315:91-6.

290. Casewell MW. The nose: an underestimated source of Staphylococcus aureus causing wound infection. J Hosp Infect 1998; $40:$ S3-11.

291. Hill RL, Fisher AP, Ware RJ, Wilson S, Casewell MW. Mupirocin for the reduction of colonization of internal jugular cannulae-a randomized controlled trial. J Hosp Infect 1990; 15:311-21.

292. Sesso R, Barbosa D, Leme IL, et al. Staphylococcus aureus prophylaxis in hemodialysis patients using central venous catheter: effect of mupirocin ointment. J Am Soc Nephrol 1998; 9:1085-92.

293. Boelaert JR, Van Landuyt HW, Godard CA, et al. Nasal mupirocin ointment decreases the incidence of Staphylococcus aureus bacteraemias in haemodialysis patients. Nephrol Dial Transplant 1993; 8:235-9.

294. Netto dos Santos KR, de Souza Fonseca L, Gontijo Filho PP. Emergence of high-level mupirocin resistance in methicillin-resistant Staphylococcus aureus isolated from Brazilian university hospitals. Infect Control Hosp Epidemiol 1996; 17:813-6.

295. Miller MA, Dascal A, Portnoy J, Mendelson J. Development of mupirocin resistance among methicillin-resistant Staphylococcus aureus after widespread use of nasal mupirocin ointment. Infect Control Hosp Epidemiol 1996; 17:811-3.

296. Lok CE, Stanley KE, Hux JE, Richardson R, Tobe SW, Conly J. Hemodialysis infection prevention with polysporin ointment. J Am Soc Nephrol 2003; 14:169-79.

297. Yahav D, Rozen-Zvi B, Gafter-Gvili A, Leibovici L, Gafter U, Paul M. Antimicrobial lock solutions for the prevention of infections associated with intravascular catheters in patients undergoing hemodialysis: systematic review and meta-analysis of randomized, controlled trials. Clin Infect Dis 2008; 47:83-93.

298. Labriola L, Crott R, Jadoul M. Preventing haemodialysis catheterrelated bacteraemia with an antimicrobial lock solution: a metaanalysis of prospective randomized trials. Nephrol Dial Transplant 2008; 23:1666-72.

299. Jaffer Y, Selby NM, Taal MW, Fluck RJ, McIntyre CW. A meta-analysis of hemodialysis catheter locking solutions in the prevention of catheter-related infection. Am J Kidney Dis 2008; 51:233-41.

300. Safdar N, Maki DG. Use of vancomycin-containing lock or flush solutions for prevention of bloodstream infection associated with central venous access devices: a meta-analysis of prospective, randomized trials. Clin Infect Dis 2006; 43:474-84.

301. Sanders J, Pithie A, Ganly P, et al. A prospective double-blind randomized trial comparing intraluminal ethanol with heparinized saline for the prevention of catheter-associated bloodstream infection in immunosuppressed haematology patients. J Antimicrob Chemother 2008; 62:809-15.

302. Schinabeck MK, Ghannoum MA. Biofilm-related indwelling medical device infections. In: Pace JL, Rupp ME, Finch RG, eds. Biofilms, infection, and antimicrobial therapy. Boca Raton: Taylor and Francis, 2006: 39-50.

303. Gristina AG. Biomaterial-centered infection: microbial adhesion versus tissue integration. Science 1987; 237:1588-95.

304. Timsit JF, Farkas JC, Boyer JM, et al. Central vein catheter-related thrombosis in intensive care patients: incidence, risks factors, and relationship with catheter-related sepsis. Chest 1998; 114:207-13.

305. Eastman ME, Khorsand M, Maki DG, et al. Central venous devicerelated infection and thrombosis in patients treated with moderate dose continuous-infusion interleukin-2. Cancer 2001; 91:806-14.

306. Abdelkefi A, Torjman L, Ladeb S, et al. Randomized trial of prevention of catheter-related bloodstream infection by continuous infusion of low-dose unfractionated heparin in patients with hematologic and oncologic disease. J Clin Oncol 2005; 23:7864-70.

307. Mermel LA, Stolz SM, Maki DG. Surface antimicrobial activity of heparin-bonded and antiseptic-impregnated vascular catheters. J Infect Dis 1993; 167:920-4. 
308. Pierce CM, Wade A, Mok Q. Heparin-bonded central venous lines reduce thrombotic and infective complications in critically ill children. Intensive Care Med 2000; 26:967-72.

309. Appelgren P, Ransjo U, Bindslev L, Espersen F, Larm O. Surface heparinization of central venous catheters reduces microbial colonization in vitro and in vivo: results from a prospective, randomized trial. Crit Care Med 1996; 24:1482-9.

310. Abdelkefi A, Achour W, Ben Othman T, et al. Use of heparin-coated central venous lines to prevent catheter-related bloodstream infection. J Support Oncol 2007; 5:273-8.

311. Carrasco MN, Bueno A, de las Cuevas C, et al. Evaluation of a triplelumen central venous heparin-coated catheter versus a catheter coated with chlorhexidine and silver sulfadiazine in critically ill patients. Intensive Care Med 2004; 30:633-8.

312. Levy JH, Hursting MJ. Heparin-induced thrombocytopenia, a prothrombotic disease. Hematol Oncol Clin North Am 2007; 21:65-88.

313. Weijmer MC, Debets-Ossenkopp YJ, Van De Vondervoort FJ, ter Wee PM. Superior antimicrobial activity of trisodium citrate over heparin for catheter locking. Nephrol Dial Transplant 2002; 17:2189-95.

314. Boraks P, Seale J, Price J, et al. Prevention of central venous catheter associated thrombosis using minidose warfarin in patients with haematological malignancies. Br J Haematol 1998; 101:483-6.

315. Bern MM, Lokich JJ, Wallach SR, et al. Very low doses of warfarin can prevent thrombosis in central venous catheters. A randomized prospective trial. Ann Intern Med 1990; 112:423-8.

316. Akl EA, Karmath G, Yosuico VED, Kim SY, Barba M, Sperati F, Cook $\mathrm{D}$, Schünemann $\mathrm{H}$. Anticoagulation for thrombosis prophylaxis in cancer patients with central venous catheters. Cochrane Database of Systematic Reviews 2007; Issue 3. Art. No.: CD006468. DOI: 10.1002/ 14651858.CD006468.pub2.

317. Akl EA, Muti P, Schunemann HJ. Anticoagulation in patients with cancer: an overview of reviews. Pol Arch Med Wewn 2008; 118:183-93.

318. Klerk CP, Smorenburg SM, Buller HR. Thrombosis prophylaxis in patient populations with a central venous catheter: a systematic review. Arch Intern Med 2003; 163:1913-21.

319. Heaton DC, Han DY, Inder A. Minidose (1 mg) warfarin as prophylaxis for central vein catheter thrombosis. Intern Med J 2002; 32:84-8.

320. Masci G, Magagnoli M, Zucali PA, et al. Minidose warfarin prophylaxis for catheter-associated thrombosis in cancer patients: can it be safely associated with fluorouracil-based chemotherapy? J Clin Oncol 2003; 21:736-9.

321. Kuter DJ. Thrombotic complications of central venous catheters in cancer patients. Oncologist 2004; 9:207-16.

322. Fontaine PJ. Performance of a new softening expanding midline catheter in home intravenous therapy patients. J Intraven Nurs 1991; 14:91-9.

323. Harwood IR, Greene LM, Kozakowski-Koch JA, Rasor JS. New peripherally inserted midline catheter: a better alternative for intravenous antibiotic therapy in patients with cystic fibrosis. Pediatr Pulmonol 1992; 12:233-9.

324. Mermel LA, Parenteau S, Tow SM. The risk of midline catheterization in hospitalized patients. A prospective study. Ann Intern Med 1995; 123:841-4.

325. Uldall PR, Merchant N, Woods F, Yarworski U, Vas S. Changing subclavian haemodialysis cannulas to reduce infection. Lancet 1981; 1:1373.

326. Cook D, Randolph A, Kernerman P, et al. Central venous catheter replacement strategies: a systematic review of the literature. Crit Care Med 1997; 25:1417-24.

327. Cobb DK, High KP, Sawyer RG, et al. A controlled trial of scheduled replacement of central venous and pulmonary-artery catheters. N Engl J Med 1992; 327:1062-8.

328. Beathard GA. Management of bacteremia associated with tunneledcuffed hemodialysis catheters. J Am Soc Nephrol 1999; 10:1045-9.
329. Duszak R Jr., Haskal ZJ, Thomas-Hawkins C, et al. Replacement of failing tunneled hemodialysis catheters through pre-existing subcutaneous tunnels: a comparison of catheter function and infection rates for de novo placements and over-the-wire exchanges. J Vasc Interv Radiol 1998; 9:321-7.

330. Robinson D, Suhocki P, Schwab SJ. Treatment of infected tunneled venous access hemodialysis catheters with guidewire exchange. Kidney Int 1998; 53:1792-4.

331. Saad TF. Bacteremia associated with tunneled, cuffed hemodialysis catheters. Am J Kidney Dis 1999; 34:1114-24.

332. Ainsworth S, Clerihew L, McGuire W. Percutaneous central venous catheters versus peripheral cannulae for delivery of parenteral nutrition in neonates. Cochrane Database of Systematic Reviews 2007; Issue 3. Art. No.: CD004219. DOI: 10.1002/14651858.CD004219. pub3.

333. Shah PS, Kalyn A, Satodia P, et al. A randomized, controlled trial of heparin versus placebo infusion to prolong the usability of peripherally placed percutaneous central venous catheters (PCVCs) in neonates: the HIP (Heparin Infusion for PCVC) study. Pediatrics 2007; 119:e284-91.

334. Jaar BG, Hermann JA, Furth SL, Briggs W, Powe NR. Septicemia in diabetic hemodialysis patients: comparison of incidence, risk factors, and mortality with nondiabetic hemodialysis patients. Am J Kidney Dis 2000; 35:282-92.

335. Powe NR, Jaar B, Furth SL, Hermann J, Briggs W. Septicemia in dialysis patients: incidence, risk factors, and prognosis. Kidney Int 1999; 55:1081-90

336. Hoen B, Paul-Dauphin A, Hestin D, Kessler M. EPIBACDIAL: a multicenter prospective study of risk factors for bacteremia in chronic hemodialysis patients. J Am Soc Nephrol 1998; 9:869-76.

337. Blot F, Chachaty E, Raynard B, Antoun S, Bourgain JL, Nitenberg G. Mechanisms and risk factors for infection of pulmonary artery catheters and introducer sheaths in cancer patients admitted to an intensive care unit. J Hosp Infect 2001; 48:289-97.

338. Kac G, Durain E, Amrein C, Herisson E, Fiemeyer A, Buu-Hoi A. Colonization and infection of pulmonary artery catheter in cardiac surgery patients: epidemiology and multivariate analysis of risk factors. Crit Care Med 2001; 29:971-5.

339. Chen YY, Yen DH, Yang YG, Liu CY, Wang FD, Chou P. Comparison between replacement at 4 days and 7 days of the infection rate for pulmonary artery catheters in an intensive care unit. Crit Care Med 2003; 31:1353-8.

340. Balagtas RC, Bell CE, Edwards LD, Levin S. Risk of local and systemic infections associated with umbilical vein catheterization: a prospective study in 86 newborn patients. Pediatrics 1971; 48:359-67.

341. Butler-O'Hara M, Buzzard CJ, Reubens L, McDermott MP, DiGrazio W, D'Angio CT. A randomized trial comparing longterm and short-term use of umbilical venous catheters in premature infants with birth weights of less than 1251 grams. Pediatrics 2006; 118:e25-35.

342. Scheer B, Perel A, Pfeiffer UJ. Clinical review: complications and risk factors of peripheral arterial catheters used for haemodynamic monitoring in anaesthesia and intensive care medicine. Crit Care 2002; 6:199-204.

343. Lorente L, Santacreu R, Martin MM, Jimenez A, Mora ML. Arterial catheter-related infection of 2,949 catheters. Crit Care 2006; 10:R83.

344. Furfaro S, Gauthier M, Lacroix J, Nadeau D, Lafleur L, Mathews S. Arterial catheter-related infections in children. A 1-year cohort analysis. Am J Dis Child 1991; 145:1037-43.

345. Rickard CM, Lipman J, Courtney M, Siversen R, Daley P. Routine changing of intravenous administration sets does not reduce colonization or infection in central venous catheters. Infect Control Hosp Epidemiol 2004; 25:650-5.

346. Hanna HA, Raad I. Blood products: a significant risk factor for longterm catheter-related bloodstream infections in cancer patients. Infect Control Hosp Epidemiol 2001; 22:165-6. 
347. Saiman L, Ludington E, Dawson JD, et al. Risk factors for Candida species colonization of neonatal intensive care unit patients. Pediatr Infect Dis J 2001; 20:1119-24.

348. Avila-Figueroa C, Goldmann DA, Richardson DK, Gray JE, Ferrari A, Freeman J. Intravenous lipid emulsions are the major determinant of coagulase-negative staphylococcal bacteremia in very low birth weight newborns. Pediatr Infect Dis J 1998; 17:10-7.

349. Crocker KS, Noga R, Filibeck DJ, Krey SH, Markovic M, Steffee WP. Microbial growth comparisons of five commercial parenteral lipid emulsions. J Parenter Enteral Nutr 1984; 8:391-5.

350. Jarvis WR, Highsmith AK. Bacterial growth and endotoxin production in lipid emulsion. J Clin Microbiol 1984; 19:17-20.

351. Karamanoglu A, Yumuk PF, Gumus M, et al. Port needles: do they need to be removed as frequently in infusional chemotherapy? J Infus Nurs 2003; 26:239-42.

352. Niel-Weise BS, Daha TJ, van den Broek PJ. Is there evidence for recommending needleless closed catheter access systems in guidelines? A systematic review of randomized controlled trials. J Hosp Infect 2006; 62:406-13.

353. Inoue $\mathrm{Y}, \mathrm{Nezu} \mathrm{R}$, Matsuda $\mathrm{H}$, et al. Prevention of catheter-related sepsis during parenteral nutrition: effect of a new connection device. J Parenter Enteral Nutr 1992; 16:581-5.

354. Yebenes JC, Vidaur L, Serra-Prat M, et al. Prevention of catheterrelated bloodstream infection in critically ill patients using a disinfectable, needle-free connector: a randomized controlled trial. Am J Infect Control 2004; 32:291-5.

355. Casey AL, Worthington T, Lambert PA, Quinn D, Faroqui MH, Elliott TS. A randomized, prospective clinical trial to assess the potential infection risk associated with the PosiFlow needleless connector. J Hosp Infect 2003; 54:288-93.

356. Esteve F, Pujol M, Limon E, et al. Bloodstream infection related to catheter connections: a prospective trial of two connection systems. J Hosp Infect 2007; 67:30-4.

357. Yebenes JC, Delgado M, Sauca G, et al. Efficacy of three different valve systems of needle-free closed connectors in avoiding access of microorganisms to endovascular catheters after incorrect handling. Crit Care Med 2008; 36:2558-61.

358. Menyhay SZ, Maki DG. Preventing central venous catheter-associated bloodstream infections: development of an antiseptic barrier cap for needleless connectors. Am J Infect Control 2008; 36:(Suppl 174): e1-5.
359. Jarvis WR, Murphy C, Hall KK, et al. Health care-associated bloodstream infections associated with negative- or positive-pressure or displacement mechanical valve needleless connectors. Clin Infect Dis 2009; 49:1821-7.

360. Menyhay SZ, Maki DG. Disinfection of needleless catheter connectors and access ports with alcohol may not prevent microbial entry: the promise of a novel antiseptic-barrier cap. Infect Control Hosp Epidemiol 2006; 27:23-7.

361. Safdar N, Maki DG. Lost in translation. Infect Control Hosp Epidemiol 2006; 27:3-7.

362. Warren DK, Yokoe DS, Climo MW, et al. Preventing catheter-associated bloodstream infections: a survey of policies for insertion and care of central venous catheters from hospitals in the prevention epicenter program. Infect Control Hosp Epidemiol 2006; 27:8-13.

363. O'Grady NP, Alexander M, Dellinger EP, et al. Guidelines for the prevention of intravascular catheter-related infections. Centers for Disease Control and Prevention. MMWR Recomm Rep 2002; 51:1-29.

364. Krein SL, Hofer TP, Kowalski CP, et al. Use of central venous catheterrelated bloodstream infection prevention practices by US hospitals. Mayo Clin Proc 2007; 82:672-8.

365. Lobo RD, Levin AS, Gomes LM, et al. Impact of an educational program and policy changes on decreasing catheter-associated bloodstream infections in a medical intensive care unit in Brazil. Am J Infect Control 2005; 33:83-7.

366. Marschall J, Leone C, Jones M, Nihill D, Fraser VJ, Warren DK. Catheter-associated bloodstream infections in general medical patients outside the intensive care unit: a surveillance study. Infect Control Hosp Epidemiol 2007; 28:905-9.

367. Rosenthal VD, McCormick RD, Guzman S, Villamayor C, Orellano PW. Effect of education and performance feedback on handwashing: the benefit of administrative support in Argentinean hospitals. Am J Infect Control 2003; 31:85-92.

368. Gastmeier P, Geffers C. Prevention of catheter-related bloodstream infections: analysis of studies published between 2002 and 2005 . J Hosp Infect 2006; 64:326-35.

369. Pronovost PJ, Goeschel CA, Colantuoni E, et al. Sustaining reductions in catheter related bloodstream infections in Michigan intensive care units: observational study. BMJ 2010; 340:c309.

370. Shapey IM, Foster MA, Whitehouse T, Jumaa P, Bion JF. Central venous catheter-related bloodstream infections: improving postinsertion catheter care. J Hosp Infect 2009; 71:117-22. 